\title{
La prescripción extintiva en un contexto de reformas. Vigencias y desfases
}

\author{
The Extinctive Prescription in a Context of Reforms. Validity and Lags
}

\author{
Abel B. Veiga Copo \\ Profesor Agregado de Derecho Mercantil \\ Universidad Pontificia Comillas de Madrid \\ aveiga@comillas.edu
}

Sumario: I. La prescripción hoy, entre la reforma y el estancamiento. -II. Qué sentido eficaz tiene la prescripción?-III. El fin último de la prescripción en un cuestionamiento de la figura.-IV. La derogabilidad de la prescripción y el pactum de non petendo.- V. Acortación y alargación de plazos. Desafío convencional a una imperatividad antigua.VI. Conclusiones.

Resumen: Pocas instituciones gozan y atesoran en Derecho el embrujo de la prescripción extintiva o liberatoria. Apenas desde la promulgación del Código civil la misma ha sufrido modificaciones, pero sí innumerables interpretaciones y posicionamientos sobre todo dogmáticos. Hoy como ayer la pregunta que debemos hacernos es si racional, amén de eficiente, la institución y la regulación que la ley depara de la misma. En ciertos extremos no podemos negar que la institución prescriptiva está entreverada de una irracionalidad manifiesta pero también arbitraria regulación, máxime a la hora de decidir cuáles son los plazos de esa prescripción, así como sus diferentes plazos en función del ámbito contractual o extracontractual. Pues ¿a qué ratio, si es que hay alguna, obedece determinar la duración de unos u otros plazos? ¿por qué la diferencia inarmónica de plazos en vez de optar por plazos holístico y únicos? El derecho internacional privado y las normas principiales han avanzado y han sugerido en este contexto tanto a nivel europeo, como a nivel de Unidroit?

Palabras clave: prescripción, exigibilidad de la obligación, término, renuncia de derechos.

Abstract: Few institutions enjoy and treasure in Law the spell of the extinctive or liberatory prescription. From the promulgation of the Civil Code it has not undergone many modifications. Nevertheless, it has been the subject of innumerable interpretations and positions, above all, dogmatic. Today as yesterday the question to be asked is whether the legal regulation of the institution is rational, as well as efficient. At certain points we can not deny that the prescriptive 
institution is mixed with a manifest irrationality, and at the same time arbitrary regulation, especially when deciding what is the term for the prescription as well as its different terms depending on the contractual or extracontractual scope. Thus, what is the ratio, if any, to determine the duration of the different terms? Why are different deadlines lacking in harmony, instead of opting for holistic and unique deadlines, as is the trend now in principled standards and frames of reference at both the European and Unidroit levels?

Keywords: prescription, enforceability of the obligation, term, waiver of rights.

\section{La prescripción hoy, entre la reforma y el estancamiento.}

Paradójicamente un instituto, per se destinado a otorgar certezas al derecho, encierra en sí mismo múltiples interrogantes y a la vez incertidumbres sobre su fundamento, su naturaleza, su objeto ${ }^{1}$. ¿Cuál es la ratio, la causa de esta institución secular y que en nuestro ordenamiento positivo ha permanecido inalterada en su configuración en los Códigos? ¿Cuál es el fundamento de la más genuina expresión de un efecto negativo que el transcurso del tiempo depara para una relación jurídica?, acaso la prescripción hasta cierto punto ¿no supone una implícita expropiación de valor de un crédito ante la inactividad del titular del mismo?², ¿por qué la discronía entre una regulación vetusta y los nuevos impulsos que trae el soft law a través de corpus principiales que están aggiornando la prescripción? ${ }^{3}$ ¿Por qué nuestro país, a diferencia de lo que está sucediendo en otros, tanto a nivel comunitario, como internacional comparado está al margen del gran debate reformador de la prescripción al menos legalmente o de lege ferenda que no doctrinalmente?

1 Acierta Cristiano Ditonno, La prescrizione (Vicalvi: Key Editore, 2018), 14 cuando señala como la simplicidad hermenéutica del instituto de la prescripción sobre el plano conceptual es contrabalanceada por las dificultades interpretativas bajo el perfil de la ratio jurídica, ámbito en el cual diversas voces doctrinales han afrontado el tema asignando diversos fundamentos, todos ellos igualmente válidos.

${ }^{2}$ En el Derecho belga, se pronuncia Cédric Eyben, «Quels délais pour la prescription?», en La prescription extinctive. Études de droit comparé, ed. por Patrice Jourdain y Patrick Wéry (Bruxelles: Bruylant, 2010), 3 y ss., especialmente 4 cuando afirma que por indispensable que sea, la prescripción extintiva constituye una técnica de expoliación.

3 Tampoco debemos dejar de lado la fallida propuesta de código mercantil de 2013 y la regulación que deparaba para la prescripción. Sobre esta, es clave la aportación de José Luis García-Pita y Lastres, «La prescripción y la caducidad en el Libro VII de la "Propuesta de Código mercantil"», Revista de Derecho Mercantil, n. ${ }^{\circ} 291$ (2014): 33 y ss. 
Amén de presentar hoy día enormes deficiencias carenciales pero no menores disfuncionalidades prácticas ${ }^{4}$. Mas, la prescripción ¿extingue o simplemente debilita un derecho? ${ }^{5}$ Perdido en ese inevitable mito de Ariadna particular, la figura de la prescripción, tan poliédrica en sí, como polivalente funcionalmente, presenta, sin embargo, una riqueza dogmática y práctica, inconmensurable, al tiempo de que su razón de ser no se funda precisamente en anclajes de justicia o equidad intrínseca ${ }^{6}$.

Y en este debate, salvo por el aspecto doctrinal dogmático, nuestro ordenamiento legal y jurisprudencial, han permanecido ajenos a un debate vivo, extraordinariamente dinámico y revulsivo sobre la prescripción que se ha vivido en las últimas décadas tanto en reformas nacionales como en la eclosión de normas principiales ${ }^{7}$.

${ }^{4}$ Gráfico y claro, Manuel Jesús Marín López, «El dies a quo del plazo de prescripción extintiva: el artículo 1969 del Código civil», La prescripción extintiva, ed. por Asociación de Profesores de Derecho Civil (Valencia: Tirant lo Blanch, 2014), 28 cuando asevera: «La regulación de la prescripción en el Código civil es obsoleta, confusa, incompleta e inadecuada, y por ello precisa de una completa reforma».

${ }^{5}$ Este punto ha sido mantenido sobre todo por Manuel Albaladejo, La prescripción extintiva (Madrid: Colegio de Registradores de la Propiedad y Mercantiles de España, 2004), 12 cuando afirma: «... creo que la prescripción no extingue nada, o sea, que después de ella, el derecho o la acción prescritos siguen tan vivos y coleando como antes, así que pueden reclamarse o ejercitarse; y si el deudor cumple está dando ejecución a lo que debe, y no realiza un acto de liberalidad a favor del titular del derecho prescrito».

${ }^{6}$ En este punto, Bruno Troisi, La prescrizione come procedimento (Napoli: Edizioni scientifiche italiane, 1980), 13 alude a estas profundas incertidumbres, que en su aspecto más significativo atañen a su naturaleza jurídica, a su estructura, a su función, por la cualificación de su fundamento, por el objeto del contenido, así como por los efectos de su operatividad. A esa justicia intrínseca apela en sus conclusiones Guillermo Orozco Pardo, De la prescripción extintiva y su interrupción en el Derecho Civil (Granada: Editorial Comares, 1995), 299 y 300 por lo que su tratamiento ha de ser restrictivo evitando con ello una aplicación desmedida y rigorista, así el de «contraderecho a negar la prestación debida» que la prescripción ganada consagra debe estar limitado en su ejercicio por la necesidad de evitar que la seguridad jurídica nos lleve a amparar situaciones que el derecho considera injustas.

${ }^{7}$ Cobran toda su relevancia las palabras de Reinhard Zimmermann/Jens Kleinschmidt, «Prescription. General Framework and Special Problems Concerning Damages Claims», en Yearbook on European Tort Law 2007, ed. por Helmut Koziol y Bárbara C. Steininger (Vienna: Springer Verlag Gmbh, 2008) 26 y ss., cuando en p. 27 señalan: «In spite of its enormous practical significance, the law of («extinctive») prescription (or: limitation periods) has for a long time led a backyard existence: It has failed to catch the attention of legal writers or of law reformers. That has changed dramatically in the course of the last three decades. The first comprehensive modern treatise appeared in 1975. Since then, the law of prescription has become, in many national legal systems, the object of in-depth examination; in August 1994 it was one of the topics canvassed at a congress of the International Academy of Comparative Law. At the same time, it became increasingly apparent that just about everywhere the law of prescription was in a very bad shape». Vid., además Christian Von Bar/Eric Clive, Principles, Definitions and Model Rules of European Private Law. Draft Common Frame of Reference (DCFR) (Munich: European Law Publishers, 2009). 
Riqueza que, no es óbice, sin embargo, para que, desde el rigor intelectual, pueda cuestionarse todo, pero también interpelarse si, por ejemplo, existen, o deberían o pudieran existir otros instrumentos legales que tengan el mismo efecto que la prescripción o cumplan una finalidad próxima, como por ejemplo, ciertos plazos para la exclusión -Ausschlussfristen - , la buena fe o la fiducia, o las reglas especiales sobre supuestos de pago. Como el, de una vez por todas, replantearnos el papel de la autonomía de la voluntad en la prescripción y decidir si verdaderamente pueden o no las partes modificar el plazo de prescripción legal por contrato, y si es así, ¿cómo y cuáles son, serían o habrían de ser los límites?

$\mathrm{Y}$ en esa riqueza, radica la incertidumbre, porque esa es precisamente la paradoja de una institución que, llamada a dotar de estabilidad, de certeza y seguridad jurídica en el tráfico económico y jurídico, deja un halo de indefinición y cierta incomprensión, pero también excesiva voluntariedad por parte del legislador - que no de las partes y su autonomía - que prefiere, o esa ha sido hasta hace bien poco, huir de la uniformidad ${ }^{8}$. No basta o es suficiente solo con modular la prescripción, o establecer tiempos de máximo, hay que reescribirla para hacerla más útil, más lógica, más dinámica. Huida de plazos, armonía y certeza en el momento del inicio del cómputo, de los efectos de la prescripción.

Han sido la adherencia continuada en el tiempo de añadidos, requisitos, excepciones a la norma común, arbitrariedad en plazos, incertidumbre absoluta y segura en el comienzo del dies a quo, además de posicionamientos clave como el efectivo conocimiento y buena fe de quién actúa defendiendo una pretensión los que, a la postre, han terminado por emponzoñar y multiplicar aristas, flancos y flecos que han hecho que la institución viva hoy día en una vorágine de debate, reforma y aggiornamento9.

$\mathrm{Y}$ tal vez lo haga porque durante mucho tiempo el prisma con que se ha querido ver la prescripción ha sido unidireccional, a la vez que único, cuando menos en el derecho civil ${ }^{10}$. Tanto en sus fundamentos como, en casi todos los intentos de construcción versus reconstrucción doctrinal, amén de prácticos, dista de existir una solución lineal y armonizada en las

${ }^{8}$ Magistralmente señalado por J.F. Van Drooghenbroeck, «La prescription libératoire: paradigme ou paradoxe de la sécurité juridique?», J.T., n. ${ }^{\circ} 6132$ (2004): 337 cuando afirma: «concebida como un arma absoluta contra la inseguridad jurídica, la prescripción liberatoria deviene a la vez en una de las principales víctimas y una de las grandes "artisanes"». Como bien señala el autor, son las incertidumbres de los plazos donde radica la controversia.

${ }^{9}$ Representativa de este sentir y obrar, el trabajo de Alain Benabent, «Les chaos du droit de la prescription extinctive», en Mélanges dédiés à Louis Boyer, (Toulouse: Presses de l'Universitè des sciences sociales de Toulouse, 1996), 123 y ss.

${ }^{10}$ Se mezclan y confluyen distintas tradiciones jurídicas, sobre todo, romanística y germana, que han terminado por perfilar, pero también miniturizar, la figura. Clave la aportación de Giuseppe Branca, «Non uso e prescrizione», Scritti in onore di Contardo Ferrini, (Milano: 1947), 169 y ss. 
legislaciones ${ }^{11}$. Lo que no empece para señalar como en los últimos años sí han existido nuevas normas sobre prescripción ${ }^{12}$; e, incluso, propuestas más ambiciosas como crear un marco común a modo de principios uniformes sobre esta institución ${ }^{13}$. No puede dejar de hacerse referencia a los Principios de Derecho Contractual Europeo - PECL - que abordan en su capítulo catorce de la Parte III, artículos 14:101 a 14:601, en 2004, la prescripción. Al lado de estos Principios, el Marco Común de Referencia, - DCFR - , que brinda en su capítulo séptimo una regulación prácticamente idéntica a aquella, en 2009. Finalmente, UNIDROIT aborda en sus Principios sobre los contratos comerciales internacionales, un capítulo, el décimo, sobre la prescripción, con una redacción mimética a los $\mathrm{PECL}^{14}$.

\section{Qué sentido eficaz tiene la prescripción?}

Algo es claro, la prescripción es una limitación, un cortafuegos radical ante la intempestividad del ejercicio de cualesquier pretensión ${ }^{15}$. La pres-

${ }^{11}$ Un rápido panorama sobre las legislaciones europeas en torno a la prescripción y relativa al seguro es, en palabras de Jérôme Kullmann, «La prescription», en Traité de droit des assurances, t. 3 (Paris: L.G.D.J., 2014), 1184: «un rapide survol des législations européennes montre une situation générale chaotique: délais, points de départ, causes d'interruption, etc., on est fort loin d'une quelconque harmonisation».

12 Pero si hay una referencia doctrinal indiscutible a nivel europeo en temas de prescripción, es sin duda, el profesor Zimmermann. Entre su obra, véase, Reinhard Zimmermann, Comparative Foundations of a European Law of Set-Off and Prescription (Cambridge: Cambridge University Press, 2002) y en la obra «... ut sit finis litium»-Grundlinien eines modernen Verjährungsrechts auf rechtsvergleichender Grundlage», JZ, n. ${ }^{\circ} 18$ (2000): 853 y ss.; vid., también, Christian Von Bar/Ulrich Drobning, The Interaction of Contract Law and Tort and Property law in Europe - A Comparative Study (Munchen: Sellier, 2004). Y desde el análisis de la reforma de 2008 francesa la aportación de Jens Kleinschmidt, «Das neue französische Verjährungsrecht», $R I W, \mathrm{n}^{\circ}{ }^{\circ} 590$ (2008): 590 y ss .

${ }^{13}$ Imprescindible en nuestro país la consulta a estos principios del artículo de Andrés Domínguez Luelmo/Henar Álvarez Álvarez, «La prescripción en los PECL y en el DCFR», InDret, 2009 [http://www.indret.com/pdf/654_es.pdf]. Sobre la prescripción en estos DCFR, véase la aportación de Salvatore Patti, «Rechtssicherheit und Gerechtigkeit im Verjährungsrecht des DCFR», Zeitschrift für Europäisches Privatrecht, n. ${ }^{\circ} 1$ (2010): 58 y ss.

14 PECL, Principles of European Contract Law (Part III); DCFR, Draft Common Frame of Reference. La última versión de los DCFR, aparece publicada en febrero de 2009 por la editorial Sellier, Principles, Definitions and Model Rules of European Private Law Draft Common Frame of Reference (DCFR). Outline Edition, Edited by Study Group on a European Civil Code/Research Group on EC Private Law.

15 Así, se ha afirmado desde la óptica del deudor, que la prescripción se basa en la conveniencia de poner un límite al ejercicio intempestivo de los derechos que garantice a todos un momento, un estado de paz y tranquilidad en el que nos sepamos a salvo de las acciones de terceros. Así, Marín López, «El dies a quo del plazo de prescripción extintiva: el artículo 1969 del Código civil», 126. 
cripción genera, amén de perseguir una finalidad de certidumbre en las relaciones jurídicas, esa pantalla de indemnidad, esa excepción favor debitoris que le permite a éste excepcionar frente al complimiento de la prestación hasta ese momento debida ${ }^{16}$. Quién paga lo hace porque debe. Quién excepciona lo hace por que puede hacerlo ${ }^{17}$.

Cortafuegos que no debilita, sino que extingue el derecho, o si se prefiere la facultad jurídica de exigir que dimana de ese derecho y que es el que acciona. Y ese cortafuegos es, paradójicamente necesario en el ordenamiento a modo de filtro natural de la existencia y duración misma de las relaciones jurídicas. Necesidad que no es incompatible con una legislación moderna, racional, flexible, clara y dinámica donde la ambigüedad, el exceso de interpretación jurisprudencial y doctrinal tengan menor cabida. Pues, ¿es lo mismo o ha de ser lo mismo la regulación sobre la prescripción aplicable a negocios jurídicos entre empresarios que cuando una de las partes es un consumidor o el contrato se celebra con consumidores? ¿han de regular algo las normas de tutela en este ámbito subjetivo en torno a la prescripción? ${ }^{18}$

Y por último, ¿qué espacio cabe dejar a la autonomía de la voluntad respecto a la prescripción y su eficacia? ${ }^{19}$, ¿debemos romper ese viejo paradigma en la prescripción tanto respecto a la renuncia, el inicio del cómputo, la duración del plazo? Pueden en suma, las partes negociar o estipular cláusulas en el contrato - más allá de un valor estético de mero estilo- que atañan, modifiquen, cambien el contenido legal-«imperativo» de la prescripción?

¿Qué inconvenientes hay, o a quién se perjudicaría, si las partes estipulasen una cláusula que durante el interin en que están negociando las consecuencias de un incumplimiento, una financiación ya vencida, suspendiese

16 Acierta Cesare M. Bianca, Diritto civile, VII. Le garanzie reali. La prescrizione (Milano: Giuffrè, 2012), 514 cuando afirma: «la prescrizione persegue una finalità di certeza dei rapporti giuridici, ma questa finalità si realizza tramite l'estinzione dei diritti trascurati nel tempo, in quanto secondo la valutazione normativa essi non corrispondono più ad un rilevante interesse dei titolari».

17 Como bien afirma Esther Arroyo Amayuelas, «Efectos de la prescripción extintiva», en La prescripción extintiva, ed. por Asociación de Profesores de Derecho Civil (Valencia: Tirant lo Blanch, 2014), 236: «si paga la deuda prescrita, no habrá pago de lo indebido». No olvidemos la rotundidad del Artículo 121-9 del código civil catalán cuando advera: No puede repetirse el pago efectuado en cumplimiento de una pretensión prescrita, aunque se haya hecho con desconocimiento de la prescripción.

${ }_{18}$ Referencia indiscutible en este punto, Rubén Stiglitz, Códigos civil y de comercio, Ley de Seguros (Buenos Aires, 2011), 414 al analizar el epígrafe «Quid de la prescripción en el contrato de seguro como contrato de consumo».

19 Se preguntan Sophie Stijns/Ilse Samoy, «La prescription extinctive: le rôle de la volonté et du comportement des parties», en La prescription extinctive. Études de droit comparé, ed. por Patrice Jourdain y Patrick Wéry (Bruxelles: Bruylant, 2010), 341: «L'autonomie de la volonté jouet-elle un rôle dans le fonctionnement de la prescription extinctive? Les parties contractantes peuvent-elles aménager le régime légal?». 
la prescripción en curso toda vez si admitimos que no es causa interruptiva por ejemplo unos contactos verbales o conversaciones? ${ }^{20} \mathrm{Si}$ admitimos la renuncia a una prescripción consumada o ganada, ¿no puede preverse de facto en la fase contractual entre las partes?, ¿qué razones sustentan tamaña limitación, más allá que un genérico cumplimiento o máxima de orden público? ¿a qué intereses en definitiva responde el instituto de la prescripción? ¿Públicos, privados, ambos simultáneamente?

Ahora bien, ¿ha sido, es y sigue siendo eficiente una institución como la prescripción al menos regulada como hasta el presente? ¿acaso no puede producir o acaba produciendo resultados inequitativos el automatismo de los plazos prescriptivos?, o si bien es cierto que el titular de la pretensión puede ejercitar la acción o la facultad que exija su crédito, ¿no estaríamos en puridad ante un ejercicio abusivo si conocida la pretensión no actúa sino al final del plazo en aras de evitar la prescripción? ${ }^{21}$ ¿y si la obligación o el crédito generase intereses?, ¿hasta qué punto hoy es admisible una figura que amén de extinguir una relación jurídica conlleva una nota de desnaturalización en el cumplimiento de las obligaciones tanto ante un acreedor que no actúa y un deudor que guarda silencio y espera?, ¿quid con la suspensión y por qué esa preferencia por lo interruptivo?

¿A quién y a qué favorece la prescripción, al acreedor estimulándole a que actúe y conserve sus derechos o al deudor que lejos de incitar al cumplimiento aguarda el transcurso necesario del tiempo prescriptivo? ¿puede negarse quizás una situación de sacrificio para el acreedor en aras de principios mayores? ${ }^{22}$

Acaso la prescripción ¿no está entreverada de una irracionalidad manifiesta pero también arbitraria a la hora de decidir cuáles son los plazos de esa prescripción, así como sus diferentes plazos en función del ámbito con-

20 Distinguen tres periodos donde el rol de la autonomía de la voluntad podría proyectarse Stijns/Samoy, «La prescription extinctive: le rôle de la volonté et du comportement des parties», 344, (I) el anterior al punto de partida del cómputo del plazo legal de la prescripción, (II) pendiente el curso de la prescripción y (III) el posterior a la adquisición de la prescripción y para estos tres periodos, tres interrogantes: (a) ¿el beneficiario de la prescripción puede renunciar al derecho de prescribir?, (b) ¿las partes pueden modificar el plazo legal de la prescripción y pactar un plazo más breve o más largo? y (c) ¿las partes pueden modificar a su conveniencia, las reglas legales de interrupción y de suspensión de la prescripción?

${ }^{21}$ Indicaba Albaladejo, La prescripción..., 21 que pueda ser abusivo depende de las circunstancias, pero ¿parece que, de por sí solo, no cabrá considerar abusivo el ejercicio dentro del plazo por muy tardío que sea, pues pensar otra cosa lo que fundamentaría sería solamente al acortamiento del plazo prescriptivo?

${ }^{22}$ Así, Marín López, «El dies a quo del plazo de prescripción extintiva: el artículo 1969 del Código civil», 18 afirma tras resaltar la enorme importancia práctica y teórica de la prescripción, como implica siempre un sacrificio para el acreedor solo justificado en aras de esa buscada seguridad jurídica. 
tractual o extracontractual? ¿pues a qué ratio, si es que hay alguna, obedece determinar la duración de unos u otros plazos?

Inactividad frente a liberación de deuda. Actuación frente a extinción, son los genuinos caballos de batalla de esta clásica institución parece que, a día de hoy, es incuestionada. Frente al paso inexorable del tiempo, un remedio, la actuación, la acción del acreedor reclamando el cumplimiento de la obligación, las causas - en suma - que interrumpen la inercia autónoma de la prescripción ${ }^{23}$. Presididas sin embargo por un matiz cum grano solis, restrictivo, taxativo, sin resquicios para la autonomía de la voluntad, salvo en la decisión de interrumpir o no actuar frente a la prescripción ${ }^{24}$. Y ese remedio, sin embargo, contiene y expone un tinte de expoliación ${ }^{25}$.

No cabe duda, que esta institución ambivalente, vertebral en el derecho de obligaciones, no solo privado sino también público, véase sino la importancia cada vez más creciente que tiene su estudio en el ámbito tributario, está de actualidad ${ }^{26}$. Las dos últimas décadas han abordado inusitadamente el estudio de la prescripción, un intento de clarificación normativa ante el bosquejo existente, de descomplejización y agilización de la materia, de análisis conflictual, de búsqueda de certezas en el comienzo del cómputo, de los efectos, del número de años, de, en suma, tutela reequilibradora de intereses.

${ }^{23}$ Sobre la acción del tiempo o el transcurso del tiempo en el derecho, véase la aportación de Pierre Hébraud, «Observations sur la notion de temps dans le droit civil», en Etudes offertes à Pierre Kayser, Tome II, ed. por Université de droit, d'économie et des sciences d'Aix-Marseille (Aix-en-Provence: Presses universitaires d'Aix-Marseille, 1979), 13.

${ }^{24}$ Acierta plenamente Marín López, «El dies a quo del plazo de prescripción extintiva: el artículo 1969 del Código civil», 30 cuando nos ofrece el marco de lo que debería ser el estudio de la prescripción y el análisis de cada uno de los elementos que lo conforman. A saber, la duración del plazo de prescripción; el inicio del cómputo del plazo; en qué casos cabe la interrupción de la prescripción; en cuáles es posible la suspensión de la prescripción; la existencia de una fecha límite más allá de la cual el titular no puede exigir la pretensión (plazos de preclusión); y si las partes pueden, mediante pacto, facilitar o hacer más difícil la prescripción de una pretensión.

${ }^{25}$ Sobre esta última afirmación, clásica por lo demás en el derecho belga, se pronuncia Eyben, «Quels délais pour la prescription?», 3 y 4 cuando afirma que por indispensable que sea, la prescripción extintiva constituye una técnica de expoliación. Y apunta: «Elle sera forcément ressentie comme une injustice par le créancier auquel elle est opposée». ¿Es la prescripción una injusticia para el acreedor que la sufre?

${ }^{26}$ Entre otros, véase el trabajo de Rodrigo Bercovitz, «Consideraciones en torno a la regulación de la prescripción en el Código Civil y en la Ley General Tributaria», en Tratado sobre la Ley General Tributaria: homenaje a Álvaro Rodríguez Bereijo, ed. por Juan Arrieta/ Miguel Ángel Collado/Juan Zornoza, (Cizur Menor: Thomson Reuters Aranzadi, 2010), 1243 y ss.; o la aportación de Manuel Guerra Reguera, Prescripción de deudas tributarias (Cizur Menor: Aranzadi, 2013). Clave el estudio de la prescripción desde la óptica de derecho público de Charles Froger, La prescription extinctive des obligations en droit public interne (Bourdeaux: Dalloz, 2015). 
Un estudio que ha supuesto o intentado, cambios en las regulaciones del Derecho de obligaciones, pero también, como hemos analizado, uniformización y armonización tanto a nivel europeo como internacional, habida cuenta de la centralidad e importancia de esta institución ${ }^{27}$.

De ahí que se aplique y predique a la vez, una visión y declamación restrictiva de la prescripción ${ }^{28 / 29}$. Una institución por sí misma con efectos radicales, corrosivos en una relación jurídica ${ }^{30}$. Y esos efectos son consecuencia de la imposición de unos plazos por el legislador que en ocasiones difiere y, por tanto, puede suponer un cuestionamiento de igualdad constitucional en función de quiénes sean los sujetos, la cualidad subjetiva, consumidor o no, de alguna de las partes ${ }^{31}$. Plazos que no son homogéneos y sí arbitrarios, a diferencia de lo que se trata de llevar a cabo con el soft law y los normas europeas e internacionales. No cabe duda que, el factor tiempo es clave en esta suerte de ecuación económico y financiera que resulta ser el contrato de seguro, tanto en su dimensión contractual por sí misma, como en la previsibilidad de los riesgos y su cobertura ${ }^{32}$.

${ }^{27}$ Exhaustivamente nos referencia todas las reformas legales, así como sus intentos tanto a nivel europeo como principal e internacional Marín López, «El dies a quo del plazo de prescripción extintiva: el artículo 1969 del Código civil», 19-28 con un abundantísimo apartado bibliográfico y legislativo.

${ }^{28}$ Como botón de muestra la sentencia del Supremo de 22 de octubre de 2009 cuando señala en su fundamento primero al analizar precisamente la prescripción de la acción de repetición de una aseguradora: «....La prescripción, según ha reiterado la jurisprudencia, debe ser interpretada restrictivamente (STS de 14 de marzo de 2007, RC n..$^{\circ}$ 262/2000), al no estar basada en principios de estricta justicia, sino de seguridad jurídica y de presunción de abandono del ejercicio del derecho ( STS de 6 de mayo de 2009 (RJ 2009, 2910), $\mathrm{RC} n .^{\circ} 292$ /2005). El dies a quo [día inicial] para el ejercicio de la acción es aquel en que puede ejercitarse, según el principio actio nondum nata non praescribitur [la acción que todavía no ha nacido no puede prescribir] (STS 27 de febrero de 2004). Este principio exige, para que la prescripción comience a correr en su contra, que la parte que propone el ejercicio de la acción disponga de los elementos fácticos y jurídicos idóneos para fundar una situación de aptitud plena para litigar».

29 Sumamente crítico con esta visión restrictiva, Albaladejo, La prescripción..., 23 y ss., y el elenco de sentencias que trae a colación.

30 Tomamos prestada esta expresión «corrosion» de Alain Sériaux, introducción a $\mathrm{La}$ prescription en droit de la responsabilité civile, de Marc Bruschi (Paris: Economica, 1999), XIII, que enfatiza precisamente que este efecto radical y corrosivo de la relación jurídica se produce ý es más sensible sobre todo en los cómputos breves y prescripciones muy cortas.

31 Reflexiona en este punto sobre si, ante esta aleatorieadad y atribución de plazos diferentes, se rozan o no límites de igualdad constitucional ante la ley, Eyben, «Quels délais pour la prescription?», 4 afirmando como el derecho de la prescripción ha venido así a convertirse en tierra fértil par la «contentieux» de la constitucionalidad de las leyes.

32 Así, Carlos Ghersi, Contrato de seguro (Buenos Aires: Astrea, 2007), 116 mantiene como el factor tiempo se convierte en determinante para el ejercicio de los derechos en forma individual, haciendo perder la acción para la ejecución de los derechos del acreedor. 
Probablemente la manifestación del tiempo, que a priori es neutro, se exterioriza en esta institución de un modo tan intenso como taumatúrgico, extintivo ${ }^{33}$.

Esa latencia, esa letargia del contrato provoca también que la seguridad jurídica y el tiempo estén entrelazados ${ }^{34}$. Y lo hace hasta tal punto que la ley establece máximos temporales para el ejercicio de acciones, de pretensiones, transcurridos los cuáles, la relación por inacción, se extingue ${ }^{35}$. Se finiquita ${ }^{36}$.

Estos máximos nada tienen que ver con el plazo de preclusión máximo o límite que, en todo caso puede imponerse legalmente para ejercitar la acción en derecho. Es decir, las normas principiales europeas, las normas del código civil alemán, las normas del código civil catalán, entre otras, sí imponen un plazo de posposición en el que, en todo caso, ha de ejercitarse la pretensión, transcurrido el cuál y salvo causas interruptivas, no cabe accionar ni tampoco apelar o alegar plazos prescriptivos. Un límite en suma de años que, transcurridos, diez, quince, veinte o treinta años no cabe ejercicio de pretensión alguna ${ }^{37}$.

33 Afirmaban Gaetano Azzariti/Gaetano Scarpello, Prescrizione e decadenza. Tutela dei diritti. Art. 2910-2969 (Bologna-Roma: Zanichelli, 1977), 201 como una de las más importantes manifestaciones de la influencia del tiempo sobre las relaciones jurídicas viene dada por el instituto de la prescripción.

${ }^{34}$ Advertían Leopoldo Alas/Demófilo De Buen/Enrique Ramos, De la usucapión (Madrid: Rústica Editorial, 1916), 8 que en el «derecho el concepto tiempo se enlaza con el de las variaciones de los fenómenos jurídicos, con el de la forma de sus cambios; y que al hablar del influjo del tiempo en las relaciones de Derecho no se hace referencia al influjo de un tiempo puro, abstraído de los fenómenos, considerado como algo sustantivo, sino al tiempo como medida de duración o expresión del cambio de los hechos o estados con eficacia jurídica».

35 Apuntaba sin embargo Jorge Giorgi, Tratado de las obligaciones en el derecho moderno, tomo VII (Madrid: Editorial Reus, 1930), 334 que «no es el tiempo, como erróneamente se dice, quien extingue o crea el Derecho de la prescripción, sino la inercia del antiguo propietario o del acreedor, por lo cual, la propiedad o el crédito, ya no se manifiestan como tales, o faltan a su finalidad».

${ }^{36}$ «El tiempo, con el concurso de otros factores, puede dar lugar a la adquisición de ciertos derechos, ... o a la extinción de un derecho, a consecuencia de su no ejercicio continuado», afirmaba José Castán, Derecho civil español, común y foral, tomo I, vol. II (Madrid: Editorial Reus, 1987), 963.

37 Entre otros véase Fernando Peña López, «El dies a quo y el plazo de prescripción de las acciones de responsabilidad por daños en el CC: criterios procedentes de algunos textos europeos de soft law y del Derecho estadounidense que podrían servir para su reforma e interpretación», Indret n. ${ }^{\circ} 1$ (2012): 10 y ss., donde aborda analizando los PECL y el DCFR los preceptos que regulan el tiempo de duración máximo (long-stop) de la prescripción, también llamado plazo de preclusión, si bien no se trata de un plazo distinto del de prescripción. Es un plazo de tiempo duración máximo lo que supone fijar una fecha límite más allá de la cual no se puede impedir que la prescripción produzca sus efectos, por motivo de suspensión o interrupción, pero que las acciones se extinguen. El código catalán incorpora una regla que establece un «plazo de preclusión de las pretensiones» de treinta años desde su nacimiento. Este plazo de preclusión no se puede suspender, pero vuelve a computarse desde el comienzo en 
Se pierde el Derecho, pues la prescripción extintiva no es sino, en puridad, una pérdida fatal del Derecho. Institución que «mata» al Derecho ${ }^{38}$. Lo que no precluye blasonar hasta cierto punto de una genuina naturaleza pragmática de la prescripción ${ }^{39}$. Pérdida basada en la inercia, la inactividad que a la postre se convierte en el motor y condicio sine qua non de la propia institución prescriptiva ${ }^{40}$.

Quién no ejerce, quién no vela, no defiende, no conserva su pretensión o su derecho, el ordenamiento no tiene por qué hacerlo prolongando indefinidamente relaciones jurídicas ${ }^{41}$. Se liquidan relaciones o situaciones inestables - latentes - para impedir su perpetuación, pero también su revisión, su relatividad transcurrido un tiempo, por lo que se otorga certidumbre a los derechos. A sensu contrario ya declaraba la sentencia del Tribunal Supremo de 20 de octubre de 1988 que «... cuando la cesación o abandono en el ejercicio de los derechos no aparece debidamente acreditada, y sí, por el contrario, lo está el afán o deseo de su mantenimiento o conservación, la estimación de la prescripción extintiva se hace imposible a menos de subvenir sus esencias.»

Otra cuestión es cuestionar el alcance y el tempus intrínseco de los plazos de la propia prescripción extintiva, ¿demasiado cortos, demasiado dis-

los casos de interrupción. Vid., sobre todo, Albert Lamarca i Marqués, «Comentari art. 12110», en Comentari a la nova regulació de la prescripció y la caducitat en el Dret civil de Catalunya, ed. por Antoni Vaquer/Albert Lamarca (Barcelona: Atelier, 2005), 221 y ss.

38 En la contestación de Juan Morros Sardá al discurso de ingreso a la Academia Gallega de Legislación y Jurisprudencia de Manuel Taboada Roca, La interrupción de la prescripción extintiva, provocada por actos del acreedor: su naturaleza, clases, requisitos y problemas que plantea (La Coruña: Academia Gallega de Jurisprudencia y Legislación, 1972), 104 define ésta como: «una institución jurídica que mata el derecho subjetivo merced al transcurso del tiempo por su inacción; pero a la vez es una exaltación de los modos defensivos frente a esta amenaza, para evitar que un derecho nacido caduque, y muera cuando puede existir un resquicio de defensa para que siga viviendo».

39 Así lo ha hecho Ditonno, La prescrizione..., 16 al responder a la exigencia pública de conferir certeza a hechos ambiguos respecto a una ausencia de manifestación de voluntad del titular del derecho.

40 No pierden actualidad las reflexiones de Edoardo Giusiana, «Appunti sulla prescrizione», Rivista di Diritto Civile, n. ${ }^{\circ}$ I (1957): 424 y ss.

41 Afirma Taboada Roca, La interrupción..., 23 la Ley protege los derechos, dotándolos para ello de una acción, con objeto de que puedan ser exigidos. Pero ello en tanto esos derechos cumplan lo fines para que fueron creados. Si dejan de cumplirlos, «porque su titular no los ejercita dentro del plazo que para ello le otorga la ley, ni se preocupa de realizar los actos conservativos para mantener la vivencia de la acción que los protege, entonces, como eso derechos dejan de desempeñar su función, la ley les retira la protección que les venía dispensando; resulta innecesaria, superflua tal protección. El acreedor que no se preocupa de cobrar su crédito, o de exigir la prestación objeto de su derecho, y ni siquiera pretende mantenerlo vivo durante el plazo que se le otorga, no tiene por qué concederla la ley una protección, que aquél no quiere y, entonces, deba cesar ésta». 
pares? Pero también saber a qué lógica responde la fijación de esos plazos y en base a qué criterios o sobre cuáles reposan la disparidad de plazos prescriptivos que existen en el derecho privado ${ }^{42}$. ¿A qué se debe esta disparidad prescriptiva? ¿a qué tanta duración diferente? ${ }^{43}$

No cabe duda que, en realidad, ha sido la jurisprudencia, con su desarrollo, no siempre armónico ni coherente el que ha terminado por destilar y depurar no pocas aristas de la prescripción, pero sobre todo en su cómputo y el dies a quo, pero también en lo interruptivo.

Ahora bien, ¿sigue siendo válido anclar la prescripción, hoy, en esa certidumbre jurídica o debemos otear otros fundamentos? ${ }^{44}$ ¿Acaso no es efecto de la propia prescripción una suerte de poena negligentiae del acreedor o titular que renuncia, siquiera tácitamente, al ejercicio en tiempo y validez de su pretensión jurídica? $\mathrm{O}$, ¿qué papel reservamos para la buena fe y la diligencia, máxime tanto en quién pudiendo claudica o abdica de sus derechos y sabiendo quién debe, espera para ver extinguida su relación jurídica ${ }^{45}$

42 Destaca precisamente en la estandarización y acortamiento de la duración de la prescripción la idea motriz de la reforma de 2001 de la prescripción en el BGB alemán. Amén de la subjetivación del inicio del período al desactivar el conocimiento del acreedor en combinación con un periodo objetivo más largo de prescripción (Höchsfrist), Helmut Grothe, Münchener Kommentar zum Bürgerlichen Gesetzbuch (München: C.H. Beck, 2006), Vorbemerkung zu § 194 BGB, Rz. 30 f.

43 Así, pone de manifiesto Eyben, «Quels délais pour la prescription?», 5 como la falta de transparencia de los plazos y la complejidad de su cómputo, «qui demeure une question d'espèce», podría incitar a un acreedor poco escrupuloso a «instrumentalizar» el plazo e prescriptción en determineto de su deudor. De ahí, que, como apunto el autor, la jurisprudencia ha desarrollado sus propios anticuerpos.

${ }^{44}$ Sobre este fundamento, la certeza de las relaciones jurídicas, tesis por otra parte dominante en la doctrina, vid. entre otros, Luca Bardaro, «Prescrizione e decadenza», en Casi di diritto privato, ed. por Fernando Greco (Roma: Neldiritto Editore, 2014), 51 y ss. Apunta Ditonno, La prescrizione..., 14 como bajo esta dimensión el instituto desarrollaría la función de consolidar algunas situaciones de hecho, donde garantiza a los consociados certeza y «affidabilità» jurídica.

45 Confronta el Derecho, la prescripción, la moral y la buena fe, Giorgi, Tratado..., 334 señalando: «La prescripción por sí misma, no es buena ni es mala en moral. Todo depende del uso que de ella se haga. Alegada por el deudor de buena fe, que cree haber pagado y extraviado el recibo, ... avalada por el silencio diario del pretendido deudor, es, no solamente una excepción legal, sino también, honrada y honesta, contra la cual ni el más severo moralista puede encontrar qué oponer... Pero en el campo de la prescripción coge el fruto prohibido por la moral, quien la opone sabiendo que no ha pagado un céntimo ... Entonces la prescripción es verdaderamente una excepción inmoral». Determina el auto de 2 de marzo de 2010 de la Audiencia Barcelona, que es criterio doctrinal: «la prescripción extintiva actúa más que por un no ejercicio por «silencio de la relación jurídica» durante el tiempo pertinente, el fundamento de la prescripción extintiva es que se entiende que abandona su derecho la persona que era su titular (STS 9 noviembre 1954). El «silencio» es el elemento fundamental de la prescripción extintiva y medida de la entidad de su eficacia frente al derecho afectado por ella; silencio y extinción son pues, términos correlativos». 
Otra cuestión es plantearnos críticamente si esa riqueza doctrinal ha sido o no en verdad un mero capricho teórico o por el contrario ha estado asido a sólidas razones y justificaciones, que no lo son si éstas solo se fijan en la arbitrariedad de marcar unos plazos u otros de vida para el ejercicio de las acciones antes de que prospere la prescripción ${ }^{46}$.

No por ello pierde complejidad pese a su elasticidad, como tampoco por ello deja de ofrecer diversas y a veces artificiosas explicaciones dogmáticas y particulares. ¿Qué decir de un concepto de prescripción? ${ }^{47}$ Desde el estatismo de algunas visiones, sin duda, una comprensión analítica y crítica de la figura es esencial ${ }^{48}$. Lo que no impide someterla a tensiones, cuando menos teóricas, a comparaciones, a construcciones dogmáticas, analíticas e incluso empíricas, pero sin perder el fin último y práctico que subyace y late a la misma, la exigibilidad tempestiva de un derecho.

No pierde sentido la apreciación hecha en su día por la Corte Constitucional italiana cuando en su considerando de derecho primero aseveró: «... Dato che la prescrizione é modo generale d'estinzione deu di-

46 Crítico, Fernando Gómez Pomar, «¿Qué hay en un número? La magia de las cifras y los plazos de prescripción», InDret, n. $^{\circ} 4$ (2015): 4 cuando afirma: «la impresión que uno tiene es que los plazos de prescripción general - y no solo estos, también plazos especialesresponden más bien a la inercia de la institución de la prescripción como parte del bagaje intelectual de los juristas - no solo privatistas, pues también se ha extendido al ámbito penal o tributario, entre otros - . Y la determinación concreta de uno u otro plazo obedece a la «magia» de un número, a ser posible redondo, con poco más detrás que intuiciones bienintencionadas sobre soluciones «equilibradas» y la influencia de modas académico-jurídicas o trasplantes de otros sistemas jurídicos».

47 Oportuno y porque parte de la reforma que se experimentó en Francia, nos ofrece Kleinschmidt, «Das neue französische Verjährungsrecht», 591 un concepto dual: «Der Begriff "prescription" hat im CCF seit jeher eine doppelte Bedeutung: Er umfasst auf der einen Seite mit der prescription extinctive die Verjährung im eigentlichen Sinne und auf der anderen Seite mit der prescription acqusitive die sachenrechtliche Ersitzung. Indem er» früher «beiden Formen der prescription einen gemeinsamen Abschnitt im Gesetz widmete, folgte der CCF - ebenso wie andere Kodifikationen des Naturrechts - dem älteren ius commune. In der Tat geht es in beiden Fällen um die Folgen des Zeitablaufs für ein Recht, doch sind diese Folgen verschieden sowie systematisch unterschiedlichen Rechtsbereichen zugewiesen. Manche Vorschriften des CCF waren daher auf beide Typen der prescription anzuwenden, andere, je nach Sachzusammenhang, nur auf den einen oder den anderen Typus. Daraus ergab sich eine häufig als unbefriedigend oder "unglücklich" bezeichnete Gemengelage von Vorschriften, die gänzlich unterschiedliche Regelungsbereiche betrafen. Die französische Rechtswissenschaft hat diese Vermischung schon lange überwunden und behandelt beide Bereiche getrennt. Der Avant-projet hat freilich gleichwohl - ohne Angabe von Gründen - tradi-tionsbewusst daran festgehalten».

48 Apunta Bianca, Diritto civile..., 514: «la prescripción persigue una finalidad de certidumbre de las relaciones jurídicas, pero esta finalidad se realiza a través de la extinción de los derechos transcurridos en el tiempo, en cuanto a la valoración normativa no corresponde más que a un relevante interés de los titulares». 
ritti, la garanzia costituzionale d'un diritto non vieta, di per sé, che esso si estingua per il decorso del tempo: la tutela costituzionale dà al diritto soggettivo una forza maggiore di quella che gli deriverebbe dalla legge ordinaria; ma non lo rende necessariamente perpetuo poiché, se alla base della prescrizione sta un'esigenza di certezza dei rapporti giuridici, questa tocca di regola qualunque diritto, compresi quelli costituzionalmente garantiti» ${ }^{49}$.

Exigibilidad que pende y depende de una voluntad, la posibilidad de decisión del titular de la acción y, en suma, del Derecho ${ }^{50}$. Pero planteamos un interrogante, ¿es conveniente y útil hoy día, preservar la institución de la prescripción? ¿sigue cumpliendo la finalidad para la que nació, ser un modo de extinción de las obligaciones al tiempo que provee al deudor de una excepción perentoria $?^{51}$ Debemos, por último, ¿seguir cercenando a la voluntad de las partes pactar extremos sobre el plazo, la duración, el inicio del cómputo, las causas interruptivas, o abrimos esta veta en aras a una mayor predisposición al cumplimiento de las obligaciones cualesquiera que sean los obligados y los acreedores en el seguro?

Hoy más que nunca es necesario el rigor y la crítica sobre el fundamento de esta figura pero también de la disparidad de plazos que, sobre la prescripción, prodiga un ordenamiento ${ }^{52}$. La rigidez interpretativa, las dudas recurrentes sobre todo en torno al dies a quo, y los anclajes principiales pero sumamente abstractos de su fundamento requieren cuando menos, tomar la distancia suficiente para cuestionar, proponer, rebatir y justificar

49 Sentencia n. ${ }^{\circ} 63$ de 1966 de la Corte Costituzionale italiana. Puede encontrarse un extracto de esta sentencia en la dirección electrónica: http://www.giurcost.org/ decisioni/1966/0063s-66.html

${ }^{50}$ Recogía el viejo § 194 BGB «El derecho de exigir de otro una acción o una omisión (pretensión) se extingue por prescripción». Añadía una nota en la traducción del BGB hecha por Carlos Melón Infante, Código civil alemán (BGB) (Barcelona: Bosch, 1955), 38, nota 155 una definición de pretensión, $\mathrm{o}$ «Anspruch» y en la que la pretensión es una facultad derivada de un derecho subjetivo; la facultad de ejercitar el contenido del derecho de que ella misma es consecuencia. El equivalente de la «Anspruch» en nuestro derecho es la acción; la equivalencia no es, sin embargo, plena, puesto que nuestra acción tiene de la «Anspruch» alemana y de la «Klage» alemana (acción propiamente dicha).

51 Como bien señala Paul Demoulin, Étude sur la prescription en matiére d'assurances terrestres (Bruxelles: Bruylant, 1945), 94: «... elle fournit au débiteur une exception péremptoire qui lui permet d'écarter la demande».

${ }^{52}$ Curiosamente hace siglo y medio ya advertía Federico Carlos Savigny, Sistema del derecho romano actual, tomo cuarto (Madrid: F. Góngora, 1879), 191: «... los legisladores modernos han fijado para las diarias relaciones de la vida, prescripciones muy cortas, cuyos plazos corresponden perfectamente a las necesidades y también al interés bien entendido de los acreedores. Debemos, por tanto, no aumentar en derecho común la dificultad de la prescripción de treinta años y hacerla casi imposible, subordinando su punto de partida a condiciones arbitrariamente creadas». 
el por qué y la esencia misma de la prescripción ${ }^{53}$. Incertidumbres, vacíos y dudas se dan cita tanto en la configuración como en la proyección de la prescripción pero, sobre todo, en la ingente casuística e hipótesis que hacen de ella una institución viva.

Nos hemos detenido quizás demasiado en los aspectos menos dinámicos de la prescripción y dejado al margen la confluencia de hechos y actos jurídicos que, a la postre, producen los efectos extintivos ${ }^{54}$.

Mas también de la duración real de la misma y la eficacia que, en su caso pueden tener plazos amplios frente a plazos más breves o exiguos ${ }^{55}$. Y ello no podemos hacerlo sin la atención puesta en la litigiosidad, sobre todo judicial, que los plazos, los cómputos generan y que han deparado no pocas situaciones erráticas y controvertidas, lo que apunta la necesidad de perfilar aristas, interpretaciones y prácticas recurrentes que, a la postre generan tanto desconcierto como ineficiencia y abstractamente, inseguridad ${ }^{56}$.

El debate hoy como ayer, se reconduce a una dualidad clara, a saber, una cuestión es la renuncia de la prescriptibilidad o imprescriptibilidad de las acciones y otra, el cuestionamiento del comienzo de los plazos prescriptivos o su transcurso. No puede renunciarse a un derecho prescriptible, es decir, si la ley configura una acción, un negocio como prescriptible, las partes no pueden inferir ni pactar la imprescriptibilidad del mismo. Y a sensu

${ }^{53}$ Pese a la reforma de 2008 en Francia, no dejó sino un regusto amargo o de cierta insatisfacción en la doctrina al no lograr reducir tipos de prescripción y plazos. Así, entre Philippe Malaurie, «La réforme de la prescription civile», Defrénois, n. ${ }^{\circ} 18$ (2008): 2029 y ss.; Anne-Marie Leroyer, «Réforme de la prescription civile», RTD.civ (2008): 563 y ss.; Denis Mazeaud, «La prescription extinctive dans les codifications savantes», D.2008: 2523 y ss.; Juliette Senchal, «La loi française sur la prescription en matière civile et l'objectif communautaire d'un droit européen des contrats plus cohérent: concordance ou dissonance?», Revue des contrats, $\mathrm{n}^{\circ} 4$ (2008): 1472 y ss.

54 Así lo reclamaba en su día Troisi, La prescrizione..., 40 cuando postulaba por la necesidad de un radical cambio de perspectiva en el estudio de la prescripción: a la tradicional visión estática debe sustituirse una perspectiva dinámica, capaz de propiciar un riguroso análisis del procedimiento de formación del tipo de prescripción.

55 Un enfoque de esta brevedad/longitud de los plazos de prescripción, pero para el derecho penal, nos lo ofrece Yair Listokin, «Efficient Time Bars? A New Rationale for the Existence of Statutes of Limitations in Criminal Law», Journal of Legal Studies, vol. 31 (2002): 99 y ss.

56 Sobre estos errores y los costes de litigación, véase la aportación de Thomas J. Miceli, «Deterrence, litigation costs, and the statute of limitations for tort suits», International Review of Law and Economics, vol. 20 (2000): 383 a 394, que nos ofrece una visión en la que la justificación convencional de la prescripción, es que la evidencia se deteriora con el tiempo, lo que aumenta la probabilidad de error legal. La longitud de un plazo prescriptivo óptimo equilibra este costo de una longitud más larga contra la dilución en la disuasión que resulta de una longitud más corta. Miceli desarrolla un modelo para mostrar que un plazo prescriptivo finito es óptimo incluso en un mundo sin error legal. La compensación implica solo los costos de litigio y la disuasión: una prescripción más corta reduce la disuasión, pero también ahorra en costos de litigio al limitar el número de demandas. 
contrario, algo que es imprescriptible, las partes no pueden acordar la prescripción, al caer fuera de la autonomía negocial la capacidad de cuestionar o negar la imprescriptibilidad legal ${ }^{57}$.

El nervio de la institución prescriptiva no es otro que el inejercicio de una acción para hacer valer o exigir una pretensión, un derecho. Inejercicio al que hay que sumar otra variable circunstancial, la falta de reconocimiento del derecho por la otra parte, el sujeto pasivo del derecho o deudor. La consecuencia, transcurrido un determinado umbral temporal y no exenta de una dosis cierta de seguridad jurídica que rompa la latencia de una situación, es la extinción del derecho mismo.

De ahí que el ejercicio de la acción rompa, interrumpa y, consecuentemente exija ese Derecho ${ }^{58}$. Actio utilis. Solo el ejercicio tempestivo del derecho rompe la prescripción y hace valer en tiempo la pretensión. Cuestión distinta es enmarcar la prescripción en la acción o en el Derecho, esto es, centrar el objeto mismo de la prescripción, pues ¿qué prescribe la acción para hacer valer la pretensión o prescribe por el contrario el derecho mismo? O planteado de otro modo, ¿prescribe la acción para hacer valer un Derecho o directamente el Derecho mismo ${ }^{59} \mathrm{O}$ prescribe la facultad jurídica que conlleva y arrastra todo Derecho subjetivo? ${ }^{60}$

La prescripción extintiva, por su parte, «extingue» obligaciones y derechos ajenos ante la inactividad del acreedor toda vez que, temporalmente, no hace valer sus pretensiones ${ }^{61}$. Actuación y tempestividad se

57 Así, Luis Díez-Picazo, La prescripción extintiva en el Código Civil y en la jurisprudencia del Tribunal Supremo (Madrid: Civitas, 2007), 63 distinguía entre prescripción consumada y prescripción futura, en base al dictado del art. 1935, artículo que impide que un derecho legalmente prescriptible se convierta en imprescriptible por voluntad de las partes.

58 Señalaba Díez-Picazo, La prescripción..., 93 que esta es un «fenómeno jurídico en virtud del cual un derecho subjetivo queda extinguido en virtud del continuado inejercicio del mismo durante un determinado lapso de tiempo establecido por la ley».

59 Así, Díez-Picazo, La prescripción..., 33 y ss., donde tras un rico debate teórico y comparado afirma p. 38 que el objeto directo e inmediato de la prescripción son las facultades jurídicas y, más concretamente, dentro de las que hemos llamado «facultades de exigir».

60 Tesis que apuntó Díez-Picazo, La prescripción..., 37 para superar la dualidad discursiva entre si lo que prescribe es la acción, el derecho subjetivo o, en este caso tal y como argumenta el autor, la facultad de exigir. Categórico afirmaba: «La prescripción no afecta de modo directo e inmediato al derecho subjetivo considerado como unidad de poder, sino únicamente a las facultades. La prescripción solo afecta al derecho subjetivo mediatamente en cuanto que lo modifica, lo limita o lo reduce».

61 Aducen Yvonne Lambert-Faivre/Laurent Leveneur, Droit des assurances (Bordeaux: Dalloz, 2017), 256 como ésta, la prescripción extintiva constituye un medio de liberarse de las propias obligaciones y «d'éteindre» de extinguir una deuda por el transcurso de un cierto lapso temporal, bajo las condiciones determinadas por la ley. La prescripción es de orden público, y no se puede renunciar de antemano. 
convierten en ejes de un derecho normalmente de crédito ante el incumplimiento de un hacer, de un dar, de un prestar por parte o bien del asegurador, o bien del asegurado.

Razones de orden público, de equidad, de equilibrio sinalagmático de las prestaciones pero también de equilibrio financiero, abonan un ámbito propicio para la prescripción. Una extinción ministerio legis, pero que, por otra parte, supone la eliminación y tiene el efecto de desaparición de la acción judicial que atesora pretendidamente un acreedor en aras de exigir el cumplimiento de una prestación toda vez que transcurra un tiempo específico marcado en la ley ${ }^{62}$.

Lo que no significa que estemos ante una figura sencilla, y donde las diferencias con la usucapión, pero sobre todo con la caducidad, abonan un campo, el de la prescripción, de enorme riqueza dogmática y constructiva ${ }^{63}$. Y como en todo, el transcurso del tiempo [el silencio del derecho] ${ }^{64}$, puede frustrar expectativas y derechos patrimoniales.

Es el inejercicio de un Derecho subjetivo, es la inactividad de quién titula una pretensión patrimonial que puede ser efectiva, la que le permite accionar o no hacerlo, en cuyo caso, la aptitud indolente o pasiva, o decidida a no ejercer sus Derechos, hace que los mismos decaigan por el mero trans-

62 In extenso, Carlos Ignacio Jaramillo, «La prescripción en el contrato de seguro», en Derecho de seguros, tomo IV, (Bogotá, 2012), 24 y ss. con importantes referencias doctrinales.

${ }^{63}$ Señalaba Díez-Picazo, La prescripción..., p. 32 como un concepto preciso y rigurosamente científico de la prescripción no puede darse, sin haber decidido antes: $1 .^{\circ}$ saber cuál es el objeto de la prescripción, es decir, saber si afecta directamente al derecho subjetivo considerado como unidad o únicamente a las acciones concedidas para hacerlo valer y defenderlo; $2 .^{\circ}$ determinar cuáles son los presupuestos de la prescripción; $3 .^{\circ}$ determinar sus efectos, lo que exige averiguar: primero, si la prescripción tiene que ser invocada por los interesados o puede, en cambio, ser acogida de oficio por el juez; segundo, si es automática o no, esto es, si sus efectos se producen o no de un modo inmediato; y, finalmente, si puede hablarse y hasta qué punto de un efecto extintivo; $4 .^{\circ}$ determinar cuáles son las verdaderas relaciones existentes entre la llamada prescripción extintiva y la llamada usucapión; por último, $5 .^{\circ}$ determinar cuáles son las verdaderas relaciones existentes entre la prescripción extintiva y la caducidad, con el fin de establecer, con la mayor claridad posible cuál es la específica diferencia que separa a la primera de la segunda. Sobre las diferencias con la caducidad, entre otros, Pedro De Pablo Contreras, «De la prescripción de las acciones», en Código civil comentado, tomo IV, ed. por Ana Cañizares (Cizur Menor: Civitas, 2016), 1544 y ss.

${ }^{64}$ Así, siguiendo a Naendrup se refería Federico De Castro, Derecho civil de España (Cizur Menor: Civitas, 2008), 145. El autor nos referencia como Alas-De Buen-Ramos, optaban por hablar de «silencio de la relación jurídica», referencia que también aducía Díez-Picazo, La prescripción..., 94, nota 4, este autor sin embargo señalaba (p. 39) que referirse al «silencio de una relación jurídica» como presupuesto de la prescripción era una idea que, sin ser inexacta, era demasiado vaga e imprecisa 
curso del tiempo ${ }^{65}$. El legitimado decidirá actuar, o no hacerlo, por lo que el ejercicio de la acción prescribirá como fruto de la inactividad o desidia del titular de la misma.

La prescripción es la plasmación más evidente que el mero transcurso del tiempo genera y provoca tanto para la adquisición como para la pérdida de derechos, según estemos ante plazos temporales de prescripción adquisitiva o, por el contrario, extintiva ${ }^{66}$; con la prescripción, en cierto sentido, se purifican y adquieren certidumbre situaciones o relaciones jurídicas que, hasta ese momento, pendían o latían en un limbo de indefinición ${ }^{67}$; la consolidación de una situación jurídico económica irreversible en aras de una estabilidad y seguridad jurídica necesaria ${ }^{68}$.

¿Quid con aquellas pretensiones cuyo ejercicio extemporáneo y distanciado en el tiempo y que dimanan de hechos y situaciones jurídicas que otros han consolidado, pudieran ejercitarse en todo tiempo y en cualquier momento?

Serán hechos, materiales, fácticos, sea por cumplimiento lo sea por incumplimiento de hacer, de dar, incluso de conductas y comportamientos colaborativos los que exigirán o impedirán a la postre la consumación de una pretensión, de un derecho patrimonial en la mayoría de los supuestos de

65 Magistral De Castro, Derecho..., 145 que refiriéndose a la prescripción extintiva y la usucapión afirmaba: «Con el término equívoco y poco expresivo de prescripción se conocen dos figuras ... en los que la continuada inactividad en el ejercicio del derecho subjetivo supone amenaza de su extinción. Implican una grave limitación en el ámbito de libertad que confieren los derechos subjetivos patrimoniales. Pues, a diferencia de otros derechos, ..., entregan al arbitrio del sujeto la posibilidad de ejercitarlos o no ejercitarlos».

${ }^{66}$ Como bien recordaba Manuel Argañarás, La prescripción extintiva (Buenos Aires: Editora Argentina, 1966), 7 siguiendo a Giorgi: «Un derecho que no se manifiesta ... por la inactividad del acreedor, es un derecho que falta a su finalidad y equivale para la humana justicia, a un derecho que no ha existido: lo cubre el olvido y lo sepulta el silencio de los años».

${ }^{67}$ La prescripción se ha fundamentado en las más variopintas bases, a saber, en el buen orden social, en la seguridad a las situaciones existentes, la evitación de pleitos, el soslayamiento de dificultades probatorias, la apariencia, la seguridad jurídica, en el mejor ambiente de la economía de mercado, pero sin duda son sobresalientes las palabras de De Castro, Derecho..., 146 cuando concluye: «Sea lo que fuere de esta búsqueda de un fundamento último para la prescripción, lo cierto es que actualmente se ha convertido en una figura aceptada por la sociedad, sin reservas y útil, posiblemente necesaria, para la limpieza y purificación drástica del tráfico jurídico, eliminando situaciones residuales que obstaculizarían el bien juego de las instituciones patrimoniales; aunque eso sea costa de ciertos resultados concretos injustos».

${ }^{68}$ Se planteaba Albaladejo, La prescripción..., 16 si prescribía el derecho o lo hacía la acción. Así, decía: «... no hay acuerdo sobre si realmente prescribe aquél o la acción que corresponde para hacerlo efectivo, o si lo que ocurre es que subsistiendo uno y otra, la llamada prescripción de los mismos, consiste sólo en que la ley faculta al sujeto pasivo para que, amparándose en el transcurso del tiempo, se niegue a hacer lo que debe, cuando se le reclame pasado el plazo de prescripción». 
seguro. Pretensión que también puede ser liberatoria, extintiva. Un orden que, en cierto sentido, penaliza la inercia o la inactividad de una de las partes que no tutela sus propias pretensiones patrimoniales y que, latente en el tiempo, termina por purgar aunque la misma genere un perjuicio para una de las partes. Así, la necesaria inactividad del acreedor durante un específico interim temporal va unida a este requisito temporal clave para que se concrete la prescripción ${ }^{69}$.

Ese transcurso temporal minora y relaja la propia percepción del contrato y sus obligaciones, extingue o dificulta cargas probatorias, aumenta deudas, grava con intereses, etc. El tiempo consolida situaciones fácticas que no deben permanecer indefinidas sine die. Mas eso si, siempre y cuando estemos ante obligaciones susceptibles de prescribir, o lo que es lo mismo a sensu contrario, que la mismas no se configuren legalmente como imprescriptibles.

Exigibilidad que pende y depende de una voluntad, la posibilidad de decisión del titular de la acción y, en suma, del derecho ${ }^{70}$.

La prescripción no solo extingue una obligación para el deudor, normalmente de claro contenido patrimonial, sino que, sobre todo y principalmente, proporciona certeza y seguridad a las relaciones jurídicas evitando la indefinición obligacional en el tiempo ${ }^{71}$. Como veremos en ulterior epígrafe los fundamentos y el anclaje racional de esta institución han sido numerosos al tiempo que acumulados sin el menor reparo. Desde la inactividad y presunción de abandono, pasando por una suerte de expropiación

${ }^{69}$ Como bien señala Jaramillo, «La prescripción en el contrato de seguro», 26 esa inactividad del acreedor se traduce en la prescripción no se haya interrumpido por ningún medio idóneo, esto es, que no haya mediado circunstancia que, de acuerdo con la normativa, implique actividad por el acreedor (opus) y, en esa medida, renueve la contabilización o decurso del término correspondiente.

${ }^{70}$ Recogía el viejo § 194 BGB «El derecho de exigir de otro una acción o una omisión (pretensión) se extingue por prescripción». Añadía una nota en la traducción del BGB hecha por Melón Infante, Código... 38, nota 155 una definición de pretensión, o «Anspruch» y en la que la pretensión es una facultad derivada de un derecho subjetivo; la facultad de ejercitar el contenido del derecho de que ella misma es consecuencia. El equivalente de la «Anspruch» en nuestro derecho es la acción; la equivalencia no es, sin embargo, plena, puesto que nuestra acción tiene de la «Anspruch» alemana y d ela «Klage» alemana (acción propiamente dicha).

${ }^{71}$ Las razones que justifican este instituto son, para Rubén Stiglitz, Derecho de seguros, tomo III, 4. ${ }^{a}$ ed. (Buenos Aires: La Ley, 2005), 364 las de seguridad de las relaciones jurídicas, el interés en liquidar situaciones inestables, impedir que determinadas situaciones de hecho puedan ser revisadas después de transcurrido cierto tiempo, la certeza de los Derechos y la seguridad jurídica que se vería comprometida si el titular del derecho podría hacerlo valer «cuando ya se han borrado de la memoria de los interesados las circunstancias del acto, y cuando es probable la destrucción de los documentos comprobatorios de la extinción del derecho, o incluso ya ha fallecido el deudor y sus herederos desconocen todo lo relativo a la obligación». 
penalizadora ante la desidia del acreedor, hasta la certidumbre y la seguridad jurídica ${ }^{72}$.

Somos conscientes de que estos son argumentos recurrentes, casi principiales, pero ¿tiene sentido, a día de hoy, seguir anclando fundamentos, naturaleza, finalidades en normas o máximas de principios? Apelar al orden público, la seguridad jurídica, la certidumbre, es sin embargo, práctico, pero no podemos olvidar que en la realidad, todo dependerá del comportamiento conductual y decisional de las partes. La prescripción no empuja al cumplimiento, puede a lo sumo, incitarla al mismo, pero si el deudor no está dispuesto a cumplir, no lo hará, al contrario, buscará beneficiarse de la prescripción, y si el acreedor no tutela su derecho, tampoco querrá ni facilitará el cumplimiento por lo que, la prescripción acabaría siendo un medio para la fatalidad de la relación jurídica.

La prescripción libera ${ }^{73}$; extingue, consolida las consecuencias de una inacción, sea ésta por las causas que sean y que solo el transcurso del tiempo acaba consolidando ${ }^{74}$. Significa y provoca la pérdida de un Derecho subjetivo. Fundamenta, paradójicamente, una excepción dándole substantia, dinamismo pero sobre todo, razón y argumento ${ }^{75}$.

Mas también es comportamiento, es actitud ante una pretensión y ante una obligación, ex ante y durante en el primer caso, durante y ex post en el segundo $^{76}$. Indefectiblemente en el seguro, las acciones que se prodigan son las in personam, no in rem, dejando al margen quizás supuestos de aseguramientos sobre propiedades con derechos reales de garantía. Como es sabido el comienzo de la prescripción para las acciones in rem es menos contro-

72 Como bien señala Arroyo Amayuelas, «Efectos de la prescripción extintiva», 238, el Tribunal Supremo y las Audiencias se sirven de estos argumentos, de forma aislada o cumulativa, y, en ocasiones, con el fin de advertir del riesgo de declarar prescritas pretensiones legítimas o bien fundadas del acreedor.

${ }^{73}$ Es para Ghersi, Contrato..., 117 un instituto destinado a dotar de seguridad jurídica al sistema (como subsistencia social de convivencia) e integra los principios centrales del derecho común, en los que puede, por imperio de las partes (cuando hay igualdad de poder de negociación), establecerse plazos diferentes que los legales y que resultan cláusulas abusivas en favor de las empresas en los contratos masivos de estructura de adhesión.

${ }^{74}$ Sobre el alcance del término liberación, y los interrogantes en torno a si efectivamente la prescripción es un modo de liberación o más bien una presunción de liberación, se pronunciaba hace un siglo Leopoldo Alas/Demófilo De Buen/Enrique Ramos, De la prescripción extintiva (Madrid: Centro de Estudios Históricos, 1918), 42.

75 Advertía Karl Larenz, Derecho civil. Parte General (Madrid: Editoriales de Derecho Reunidas, 1978), 328 la prescripción no es una causa de extinción, sino el fundamento para una excepción.

76 Decía José Puig Brutau, Caducidad, prescripción extintiva y usucapión (Barcelona: Bosch, 1988), 4 como el transcurso del tiempo es un elemento importante tanto en la usucapión como en la prescripción extintiva; pero lo decisivo es lo que tanto el titular de derechos reales como el acreedor hayan hecho o dejado de hacer durante su transcurso. 
vertido que respecto de las acciones in personam. El cómputo de la prescripción de una acción personal comienza a correr en el momento en que se falta al cumplimiento de una obligación ${ }^{77}$.

Pero, ¿es racional pensar que lo que las partes acuerdan ex ante es lo que verdaderamente querían ambas? Pensemos en un seguro, las partes ¿hubiesen aceptado otro acuerdo o contrato de seguro para evitar a posteriori una interpretación contractual habida cuenta que el anterior presentaba vacíos, lagunas o desnaturalizaciones? ¿voluntad hipotética o real? O es que acaso cuando proceda, si es que procede, la labor interpretativa el resultado de la misma no refleja lo que hipotética pero realmente hubieran querido las partes ex ante? Interpretar significa explicitar y especificar el contenido contractual. Un asegurado, como cualquier consumidor, no tiene una información completa, al menos precontractualmente, de todos los riesgos que corre, ni de su intensidad, frecuencia, siniestralidad, etc., por lo que su capacidad de análisis y evaluación está limitada. Asignar eficiente y racionalmente esos riesgos no es sencillo, ni tampoco cae cien por cien del lado de la balanza del asegurado.

Cooperar significa cesión, concesión en aras a llegar a un acuerdo final, en este caso de seguro, el límite la no desnaturalización del contrato y la ruptura del sinalagma genético que rompa el equilibrio y provoque que el mismo sea excesivamente oneroso para una de las partes. Conviene por otra parte no olvidar que, dentro de ese ideal marco de elección racionales, surgen tensiones, por lo que el seguro también presenta conflicto. Cooperación como sustento de elecciones y acuerdos racionales, donde se gana y maximiza la utilidad y el beneficio. Es obvio que, si las partes cumplen sus obligaciones y deberes, la cooperación gana, cuando el conflicto triunfa significa que la cooperación no es posible ${ }^{78}$.

¿Cuáles son, por tanto, los costes de contratar en estos escenarios y cuáles los riesgos reales de que el contrato sea interpretado para alcanzar un acuerdo racional y verdaderamente eficiente para las partes, pero a la vez equilibrado? ¿Y los de negociar en una hipótesis de suspensión o de interrupción de la prescripción?

Frente a esos costes, serán los tribunales los que apliquen recursos de transacción exógenos que completen y también purguen ciertas condiciones o cláu-

77 Manifestaba y añadía además Savigny, Sistema..., 189 como además hacía falta un elemento más, a saber, sin el consentimiento del titular. Indica como tampoco es necesario que el deudor haya sido requerido a cumplir su obligación y haya faltado dicho cumplimiento. De igual modo no tienen aplicación a este punto las condiciones especiales exigidas para constituir la mora.

78 Así, Robert Axelrod, The evolution of cooperation (New York: Basic Books, 1984), 23 abogaba porque la cooperación no es posible si la decisión de cooperar se adopta de una vez y para siempre. Y esa imposibilidad se reduce a una razón esencial, a saber, la traición será la estrategia dominante. 
sulas contractuales. Ahora bien, si esto es así, ¿saben las partes, sobre todo, el consumidor de seguros, que la racionalidad eficiente de un contrato se obtiene por esta vía?, y sobre todo, ¿le compensa $a b$ initio desde el momento precontractual prever que la información asimétrica ha de completarse e interpretarse por la vía judicial interpretativa?, o ¿solo le compensa cuando cree que de no hacerlo sufrirá un perjuicio, entiéndase no indemnización, no riesgo ${ }^{79}$ ?

Las partes buscan su utilidad, y esa utilidad mutua significa colaboración, cooperación, no confrontación de utilidades aunque sean disímiles cada una; significa además maximizar el beneficio o la ventaja, sea trasladando un riesgo que no se desea asumir o asumiéndolo en una base mutual y estadística que lo dispersa en un ingente número a cambio de un precio, y minimizar por tanto el daño o el perjuicio, que puede ser tanto contractual como es la infracción de ciertos deberes precontractuales como de ejecución obligacional del contrato, como los perjuicios que el siniestro supone para cada parte, para una cobrando la indemnización que de lo contrario pecharía con las consecuencias del daño sobre su propio patrimonio o persona, para el otro, dispersando ese siniestro en esa mutualidad de seguros que componen su cartera de seguros o reaseguro, habida cuenta la imposibilidad estadística de que todos los asegurados sufran un siniestro simultáneamente en el tiempo. Y significa, cómo no, evitar el perjuicio de una de las partes, o lo que es lo mismo que el beneficio no vaya en detrimento de un perjuicio para la otra.

Pero esta búsqueda también evidencia que el contrato de seguro se asiente y, por ende, debe superar problemas de desequilibrio formal y material en la generación del contrato, y ello en base a la desinformación y el distinto tratamiento que la norma dispensa para cada una de las partes del contrato ante este déficit. Información exigible como cortocircuito del desequilibrio y la desigualdad de acceso a la misma para una de las partes.

\section{El fin último de la prescripción en un cuestionamiento de la figura}

Pero ¿acaso la prescripción tiene como fin último y fundamento causal solo la liberación del deudor de su obligación y, por tanto, de la rela-

79 Afirma Jules Coleman, Riesgos y daños (Madrid: Marcial Pons, 2010), 187 como en muchos sentidos, los tribunales no estarán en una mejor posición que los individuos para determinar qué asignación de riesgos maximizará la riqueza, y en general estarán en una posición considerablemente peor. Aunque el tribunal busque promover la eficiencia mediante la aplicación de la regla supletoria relevante, no hay razón para pensar que será más eficiente que los contratantes particulares. Un tribunal con criterio intentará que los litigantes resuelvan el problema privadamente, siempre que estén en la mejor posición para resguardarse contra el fracaso del contrato. 
ción jurídica ${ }^{80} \mathrm{O}$ debemos por el contrario abogar ¿por una aplicación restrictiva de la propia prescripción para que, en caso de duda, favorecer la subsistencia de la acción de Derecho? ${ }^{81}$ Ahora bien, preguntémonos a quién favorece realmente la prescripción. ¿Sabe el acreedor, sabe el deudor lo que es la prescripción, y sobre todo, si puede negociar o no su alcance?

Funcionalmente, más allá de los clásicos fundamentos y anclajes de la prescripción, se revaloriza la liberación de la contraparte ante el no hacer, ante la no reclamación del acreedor y la fuerza de la excepción del deudor ${ }^{82}$. Hasta cierto punto puede afirmarse que, tras el transcurso de un umbral temporal determinado y la intencionalidad de la inactividad del acreedor, el legislador ha optado por proteger al deudor ${ }^{83}$.

Decide no actuar y diluir, extinguir, su pretensión. Ello no impide que, en realidad, lata en el fondo de la prescripción un cierto, cuando no mínimo, reproche moral a la desidia o desinterés del propio acreedor y un premio, la liberación, al deudor que no cumple motu proprio, sino que espera a que se le reclame la pretensión. ¿Son de buena fe quién pudiendo actuar no lo hace y quién pudiendo reconocer tampoco lo hace? Ello sin olvidar el carácter imperativo que algunas normas, también del seguro, otorgan y confieren al seguro ${ }^{84}$.

Una inercia, una inactividad sostenida en el tiempo que, aunado al no reconocimiento de la deuda por el deudor, extingue el vínculo y la

${ }^{80}$ Para Alas/De Buen/Ramos, De la prescripción..., 263 la prescripción extintiva produce sus efectos ipso iure, y, por lo tanto, es lo mismo la renuncia realizada antes o después de haber sido alegada, siempre que la prescripción reúna todos los requisitos para producir efecto. La prescripción es un modo de liberarse que proporciona al por ella favorecido, el derecho a no cumplir la obligación.

${ }^{81}$ La opción por mantener vivo el derecho, no es sino el corolario de abogar por una interpretación restrictiva de la prescripción liberatoria. Defensor de esta vía Ghersi, Contrato..., 125.

82 El parágrafo 194 BGB al regular la prescripción parte de un axioma claro, funcional, práctico, a saber: «El derecho a exigir que otro haga o no haga (Anspruch) está sujeto a la prescripción».

83 Sobre este punto y explicando los motivos e irracionalidades del comportamiento del acreedor y su intencionalidad, vid., en profundidad, Alberto Auricchio, Appunti sulla prescrizione (Napoli: Jovene, 1971), 33 y ss. Por su parte, Angelo Falzea, voce «Efficacia giuridica», en Enciclopedia del Diritto, vol. XIV (Milano: Giuffrè, 1965), 502 incluye a la prescripción desde este punto de vista liberatorio dentro de la categoría de hechos que tienen eficacia preclusiva en sentido sustancial. Crítico con esta postura, Troisi, La prescrizione..., 76 y ss., denostando los argumentos de la preclusión.

${ }_{84}$ Así, entre otras, la ley belga de 1992 de seguro que otorga en su articulo 3 un claro carácter imperativo a los artículos 34 y 35 relativos a la prescripción. Vid., entre otros, Joëlle Tinant, «Délais et prescriptions en droit des assurances», en Les prescriptions et les délais: Actes du colloque organisé par la Conférence libre du Jeune Barreau de Liège, le 25 mai 2007 (Liège: Éditions du Jeune Barreau de Liège, 2007), 65 y ss. 
causa obligacional ${ }^{85}$. Dos hechos jurídicos, no solo fácticos, el no actuar y el no reconocer, eliminan la obligación. El comportamiento inerte del sujeto titular del Derecho en cuestión acaba modificando radicalmente la relación hasta el punto de la prescriptibilidad de la exigibilidad del Derecho mismo. El deudor quedará fácticamente investido de una potestad tal que su ejercicio acarreará la extinción del vínculo contractual por prescripción.

Ahora bien, ¿qué ocurre cuando esta actitud es debida a causas que impiden esa tutela o ejercicio de sus Derechos por el titular? ${ }^{96}$ Los actos impeditivos de una acción, de una tutela o defensa, son el parámetro opuesto a la elección o a la negligencia de no actuar y hacer valer un Derecho propio. Si no se interrumpe o no se suspende el transcurrir de la propia prescripción por quién titula el Derecho o la pretensión, el reproche culpabilístico a priori se abre paso, por el contrario, si se plantea cualesquier acto interruptivo de aquella, prima una impronta de autorresponsabilidad por parte del titular. Interrumpir la prescripción es el exponente más claro de la vitalidad del propio Derecho ${ }^{87}$. Pero ¿es actuar autorresponsable y diligentemente en la preservación de una pretensión? ${ }^{88}$

Un estado de Derecho preexistente se transforma, muta, cambia con la prescripción extintiva ${ }^{89}$. La prescripción requiere y necesita de una actua-

85 Admitía Troisi, $L a$ prescrizione..., 87 como bastará observar que el principio de la certidumbre de las situaciones subjetivas constituye, por así decir, solamente el mínimo común denominador funcional de la fase llamada preliminar del procedimiento y está sobre el fondo de la llamada prescriptibilidad.

86 Acierta Remo Caponi, «Gli impedimenti all'esercizio dei diritti nella disciplina della prescrizione», Rivista di Diritto Civile, vol. 6 (1996): 729 cuando afirma: «L'inattività del titolare può essere considerata un indice sicuro del suo disinteresse o comunque della sua incuria rispetto all'esercizio della propria situazione soggettiva, incuria e disinteresse che la prescrizione tende a colpire, qualora l'ordinamento attribuisca rilevanza in via generale sulla durata o sul decorso del termine di prescrizione ai fatti non imputabili che impediscono l'esercizio del diritto. Altrimenti, qualora a tali ostacoli non sia attribuita rilevanza o comunque ad essi sia attribuita una rilevanza episodica, l'inattività del soggetto possiede un'intrinseca carica di ambiguità, potendo essere sia la conseguenza della scelta del soggetto di rinunciare alla realizzazione del proprio interesse (o della sua negligenza), che la conseguenza di un impedimento (a lui non imputabile) all'esercizio del diritto».

${ }^{87}$ En este punto, viendo en los actos interruptivos índices de vitalidad del derecho del acreedor, Alexander Grawein, Verjährung und gesetzliche Befristung (Leipzig: Civilrechtliche Grundlegung, 1880, [reedición de 2013]), 55; Christian Weiss, Verjährung und gesetzliche Befristung nach dem bürgerlichen Rechte des deutschen Reichs (München, 1905), 11 y ss.

${ }^{88}$ Niegan que el hecho de interrumpir la prescripción sea en realidad un acto de ejercicio, Auricchio, Appunti..., 93 y ss.; también Renato Oriani, Processo di cognizione e interruzione della prescrizione (Napoli: Jovene, 1977), 170 y ss.

${ }^{89}$ Conforme Quintus Mucius Scaevola, Código civil, tomo XXXII (Madrid: Instituto Editorial Reus, 1965), 222 que infiere como lo que desaparece en la extintiva por prescrip- 
ción subjetiva que se ve constreñida por plazos temporales de cara a transformar un estado, una situación jurídica ${ }^{90}$. Es efectivamente el no ejercicio de esa actividad la que rompe y transforma ese estado de Derecho diluyéndolo, perdiendo el crédito que suele subyacer y sustentar paralelamente a esa situación jurídica obligacional, la reclamación, la indemnización, etc ${ }^{91}$. ¿Hasta qué punto sería admisible exigir al deudor la prestación, transcurridos los plazos legales que la norma marca y su conservación? ${ }^{92}$ ¿cómo opera a sensu contrario la mora?

Evitando la inestabilidad, la contingencia temporal de preservar real o artificiosamente en el tiempo obligaciones, por lo que, en puridad, la misma, libera. Preguntarse por la ratio última de la prescripción, su finalidad teleológica, la razón de ser y sobre todo, hacerlo desde la óptica dual de la dimensión subjetiva acreedor versus deudor, resulta imprescindible $^{93}$.

Al lado de esta inacción o abandono de derecho, del transcurso del tiempo, está también una omisión clara, pero a la vez deliberada, la falta de reconocimiento de la pretensión por parte del deudor. Mas, ¿cabe hablar hipotéticamente de ignorancia subjetiva frente a la prescripción? Todos ellos son elementos necesarios y concurrentes en el tiempo, pero son todos ¿causas eficientes de la prescripción?, es en todo caso la prescripción extintiva ¿un modo y causa de extinción de las obligaciones? Derechos que pierden su vigor, su esencia que, aunque sin desnaturalizarse se convierten solo en una naturalis obligatio ${ }^{94}$. Cuestión distinta es que, en-

ción es, precisamente el estado o situación jurídica obligacional, no ejercitada en sazón. En la usucapión supone hacer adquirir el dominio a la persona que, simplemente, de facto, tenía la posesión de la cosa durante determinado tiempo.

90 Nos recuerdan Azzariti/Scarpello, Prescrizione..., 204 como en un momento determinado la doctrina excluyó al valorar la inercia del titular del derecho, que ésta respondiera a una «mancata difesa del diritto violato», exigiendo como presupuesto indispensable para la prescriptibilidad un estado de hecho «contraddicente» al derecho.

91 Ancla la razón de la prescripción en la oportunidad de adecuación de una situación de facto en una situación de derecho Francesco Santoro Passarelli, Dottrine generali del diritto civile (Napoli: Jovene, 1978), 113 y ss.

92 Interrogante que contesta, categórico, Caponi, «Gli impedimenti all'esercizio dei diritti nella disciplina della prescrizione», 728: «Non si può esigere infatti che il debitore conservi a distanza di anni la quietanza dei pagamenti effettuati, perché ciò renderebbe doveroso un comportamento superiore allo standard della diligenza ordinaria».

93 Fundamentan esa ratio Milena Pafumi/Santo Spagnolo, La prescrizione assicurativa (Milano: Giuffrè, 2014), 3 en la certeza a las relaciones jurídicas.

${ }^{94}$ De ahí que autores como Ghersi, Contrato..., 125 aún aboguen por ver en la prescripción una liberación no definitiva, pues al ser o convertirse el derecho que pierde su acción en una obligación natural, el deudor que paga su deuda le permite al acreedor retener lo abonado con justo título. 
tre los efectos de la prescripción, sea el de dejar subsistente una obligación natural ${ }^{95}$.

No cabe duda que, ésta es la posición del legislador, categórica y cerrada cuando en el artículo 1930 del código civil se asevera que «se extinguen del propio modo por la prescripción los derechos y las acciones de cualquier clase que sean». Indubitada la extinción o muerte del derecho, queda sin embargo por escrutar si lo que se extingue es el derecho y la acción o sólo aquél desde la óptica sustantiva o ambas desde una óptica también procesalista instrumental pues es la acción la que hace valer y canaliza la exigencia del derecho ${ }^{96}$.

Evitar indefinidamente en el tiempo la pendencia de ciertas obligaciones y con ellas vínculos de indefinición e incertidumbre, estimular el ejercicio tempestivo de las pretensiones de todo acreedor, penalizar el no ejercicio y liberar de la deuda con todos los efectos que eso puede suponer personal, pero, sobre todo, económica y patrimonial cuando no financieramente para todo deudor, fundamentan sin duda la esencia de la prescripción.

Adviértase que, en cierto sentido, es el mero transcurso del tiempo el que opera como una causa de extinción de los Derechos y como medio de defensa extraordinariamente taumatúrgico frente a las acciones personales. Al lado habrá que analizar situaciones de auto-responsabilidad causales, en el sentido si es o no imputable al acreedor el no ejercicio del derecho o si ha habido impedimentos para llevarlo a cabo y a qué se debe, como también analizar el rol que pueden tener terceros de cara a oponerse al ejercicio o inejercicio de las partes que, tiene como consecuencia, la prescripción ${ }^{97}$.

95 Se cuestiona precisamente este efecto Savigny, Sistema..., pero sobre todo Alas/De Buen/Ramos, De la prescripción..., 257 cuando afirman que la obligación natural nace de una colisión entre las normas vigentes y el derecho justo. Éste obliga a una persona cuando aquéllas no le obligan. Y sin duda en p. 258 queda clara la posición: «Fundada la prescripción extintiva en el interés social, siendo, por lo tanto, una institución justa, debe conceder una vez cumplida derechos perfectos. ¿Qué esos derechos lesionan intereses dignos de protección? Pues mayor protección merece el interés de la sociedad entera, que exige que las relaciones jurídicas no silencien durante demasiado tiempo. Eso no obsta para que luego, el que se haya enriquecido de una manera que él repute injusta, procure remediar la injusticia; pero esto debe ser cuestión de la íntima conciencia de cada uno, en la cual no se debe mezclar la ley».

96 Afirmaban bajo el controvertido estudio del objeto de la prescripción Alas/De Buen/ Ramos, De la prescripción..., 45 que es el derecho lo que se extingue, «pero como la acción no es otra cosa que el derecho mismo, y cuando se extingue la acción, se extingue el derecho, no hay inconveniente en decir que lo que se extingue es la acción».

97 Sobre la oponibilidad de la prescripción por parte de terceros, fundamental el trabajo de Enrico Minervini, La prescrizione ed i terzi (Napoli: Edizioni Scientifiche Italiane, 1994), 7 y ss. 
O situaciones que, en apariencia, no deben ser imputables al titular del derecho pero que se encuentra imposibilitado, por ignorancia, por supeditación a una decisión o voluntad de la otra parte, porque el beneficiario o el tercero víctima ignoran a quién dirigir su acción en pro del resarcimiento del daño, las dificultades de cuantificar el crédito, la no comunicación y por tanto el no conocimiento de un cambio de domicilio del deudor, constituyen per se imposibilidades fácticas a priori para poder ejercitar el derecho o la pretensión, pero que, per se, no paralizan el correr de la prescripción.

Otra cuestión es el origen, la función, el planteamiento, la excepción de ésta ${ }^{98}$. Excepción bidireccional en realidad, pues no solo el deudor puede oponer la excepción de prescripción para el no pago, también puede hacerlo el acreedor. Imaginemos el supuesto de que para evitar la mora credendi, el acreedor excepciona la prescripción ${ }^{99}$.

Un instituto, el prescriptivo, que ha de invocarse por el interesado, hacerse valer, por vía de acción o por el contrario de excepción ${ }^{100}$; que no opera de oficio ni automáticamente, y que lo hace, con eficacia taumatúrgica tanto en un contexto judicial como extrajudicial ${ }^{101}$. Y en un sentido amplio ese hacerse valer significa también plantear y enervar las causas que pueden interrumpir el decorrer prescriptivo, como medios idóneos conservativos, si quiera, coyuntural y circunstancialmente de la pretensión ${ }^{102}$.

El silencio, la inactividad lo es o puede ser tanto de pretensiones principales como de los propios medios conservativos de éstos que el Derecho

98 Señalaba Scaevola, Código..., 219 que estamos en presencia de una institución que, si es unánimemente acogida y regulada por el Derecho positivo de todos los tiempos y de la generalidad de los países, no logra, a través del transcurso de aquellos ni de la cuidada regulación en los ordenamientos jurídicos, que éstos vean perfilada su fisonomía conceptual.

99 Vid., en este punto, Troisi, $L a$ prescrizione..., 81.

100 Crítico Albaladejo, La prescripción..., 21 aduce: «Sólo inexactamente cabe decir que tal transcurso permite suponerlo abandonado. Ciertamente que, aunque constase la voluntad de no abandonarlo, prescribiría igualmente. Y afirmar que es que no se admite más prueba del no abandono que la de haberlo ejercitado, es poder de relieve que realmente lo que importa no es el abandono presunto, sino el no ejercicio».

101 Como bien se ha argumentado la excepción supone una idea o expresión que sirve, como la acción, al derecho mismo y que por tal accesoriedad, separación conceptual y dependencia no puede técnicamente identificarse con él. Porque la acción y la excepción suponen la simple exteriorización o puesta en marcha del derecho que le sirve de soporte y contenido jurídico. Se excepciona de prescripción, como se excepciona de ausencia de personalidad en el actor, pero ésta y aquélla son facultades o defensas que sirven para hacer valer procesalmente, por medio de la excepción misma, determinados medios sustantivos por los que se prueba la improsperabilidad de la pretensión contraria. Cfr. Scaevola, Código..., 233.

102 Esta vía ya la anticipaba Grawein, Verjährung..., 55 cuando veía en la prescripción la extinción de una exigencia a consecuencia de no haber ejercitado durante un cierto tiempo ninguno de los actos considerados por la ley como causas de interrupción». 
ofrece $^{103}$. Y como en cualesquiera otras instituciones, por consiguiente, la producción de la prescripción se supedita a la actividad del sujeto que resulta obligado en esa relación jurídica llamada a prescribir ${ }^{104}$.

Frente a la actividad de un sujeto paradójicamente se contrapone, además, la inactividad, la abstención de sus derechos o el cuidado propio de éstos para hacerlos exigibles ${ }^{105}$. Es el no ejercicio el vértice de la institución, pero ¿qué ocurre cuando el ejercicio es tardío o extemporáneo? El no ejercicio ex ante, durante y para el que ya, y salvo supuestos de renuncia del deudor a plantear la prescripción, el ejercicio ex post, que, aun siendo exigible la obligación, éste último supuesto de extemporaneidad cae en los brazos de una obligación natural y la voluntariedad en el pago del deudor. Pero si nos detenemos en realidad en esa inacción, lo que en el fondo late, es una pasividad total a la hora de plantear cualquier medida de preservación e integración de la pretensión misma, del derecho.

No es solo que el acreedor que no ejercita sus derechos no solicite el cumplimiento sino que tampoco desarrollará positivamente cualquier acto, medida que permita la seguridad, conservación, tutela e integridad de su derecho durante el plazo que la prescripción está corriendo ${ }^{106}$. El acreedor, el titular de la pretensión no neutraliza el inexorable paso del tiempo en la relación jurídica «limitada», tampoco activa los medios y remedios que lo puedan paralizar para sustentar proactivamente su derecho o pretensión.

Nada tiene que ver esta situación con trazar el exacto momento en que el derecho nace y por tanto la acción activa su tutela. Momento donde la exigibilidad cobra todo su protagonismo, saber, perimetrar, conocer el momento exacto en que una obligación es exigible, lo que implica marcar el tiempo en el que la acción que la hace exigible nace y consigue o busca al menos su efectividad.

103 Pero el silencio prolongado del acreedor, hace de él un «créateur de croyance légitime»? vid. sobre el comportamiento del acreedor, Stijns/Samoy, «La prescription extinctive: le rôle de la volonté et du comportement des parties», 357.

104 Nuevamente Scaevola, Código..., 223 afirma como la prescripción consiste en el no ejercicio del derecho durante el plazo señalado por la ley.

105 Aquí radica una de las grandes diferencias entre la prescripción extintiva y la adquisitiva o usucapión. En efecto, en ésta última un titular actúa, el otro no, por lo que, aunque el titular (anterior dominical) permanezca inactivo durante el plazo temporal que traza la ley para que el dominio y otros Derechos reales prescriban, unos u otros se han extinguido. Es la posesión pacífica e ininterrumpida la que acaba consolidando sin necesidad de reclamar nada que realiza el usucapiente que preserva esa posesión con justo título y buena fe la que adquiere - actuación positiva - y de paso, extingue el derecho del antiguo titular que no ha actuado. En la extintiva es el no ejercicio del titular del crédito o Derecho el que lo acaba perjudicando por el transcurso del tiempo.

106 Señalaba Grawein, Verjährung..., 51 con una fuerte dosis de crítica hacia la inacción y ese prescriptibilidad como si la prescripción supusiese una extinción de una exigencia por su continuado no ejercicio, sería incomprensible que una Ansprüche prescriptible sobreviviera al plazo de la prescripción. 
Pensemos en aquellas obligaciones sometidas a condición, pendente conditione, ¿cómo se concilia la condición con la prescripción? ${ }^{107}$ Tanto en una condición suspensiva, como resolutoria, dejemos al margen las modificativas, es necesario que la condición se dé o que el término, el plazo, transcurra ${ }^{108}$. Cuando una obligación solo es en parte o parcialmente exigible, cada parte de la obligación a medida que es exigible atesora su prescripción propia del resto, que lo hará cuando la exigibilidad sea manifiesta ${ }^{109}$.

Cerramos este epígrafe recalcando el embrujo en el que se interrelacionan dos dimensiones únicas y esenciales, el tiempo y el Derecho ${ }^{110}$. Lo hace incluso ante el silencio que, en su momento, abrigaron tanto los Códigos de comercio como el civil respecto al seguro y, donde a excepción de la prescripción para el seguro marítimo que sí regulaba el de comercio, había que acudir al plazo general de los quince años - hoy cincoque deparaba el artículo 1964 civil o el de exiguo de un año para la responsabilidad civil aquiliana en su caso ${ }^{111}$. Y a ese silencio, unamos, otro más próximo que no remoto, el del acreedor y el del titular, silencios an-

107 Afirmaba de modo categórico Savigny, Sistema..., 187: «Para todas las obligaciones condicionales sin excepción, la prescripción no comienza hasta que la condición se cumple, y sin embargo, hay condiciones verdaderas cuyo cumplimiento depende únicamente de la voluntad del titular, respecto a las cuales, si se siguiera al regla antedicha, la prescripción debería comenzar antes de que la condición se cumpliese».

108 Categóricos señalaban Alas/De Buen/Ramos, De la prescripción..., 13 la prescripción de las obligaciones comienza cuando éstas son exigibles.

109 Por su parte, aduce Manuela Rinaldi, «La prescrizione in generale», en Prescrizione e decadenza, ed. por Luigi Viola (Milanofiori Assago: CEDAM, 2015), 45 como la condición es un elemento accidental del contrato introducido por la voluntad de las partes, con el fin de subordinar el inicio o el cese de la eficacia del mismo al verificarse el avenimiento de un cierto hecho futuro e incierto.

110 Desde este enfoque, véase la inteligente y cuasi filosófica aportación de Giacomo Travaglino, «Le stagione della prescrizione estintiva», Questione Giustizia, n. ${ }^{\circ} 1$ (2017): 49: «La prescrizione coniugata col tempo che scorre è la forma di una tutela estinta? O piuttosto di estinzione tutelata? Scopo della prescrizione è davvero quello «della difesa del presente di fronte al passato»? È forse l'immagine della estinzione tutelata che induce (nella pur probabile inconsapevolezza del legislatore) ad una prima riflessione: benché giunto all'epilogo della sua storia, alla sua estinzione per il passare del tempo, il primo significante dell'ordinamento civilistico tradizionale, il diritto soggettivo, pare ancora imporre una sorta di tutela postuma, rispettosa e sollecita (quantunque residuale, quand'anche eventuale), benché apparentemente cancellato dalla sfera del rilevante giuridico».

111 Crítico con la técnica modificativa pero también finalista de esta modificación, Gómez Pomar, «¿Qué hay en un número? La magia de las cifras y los plazos de prescripción», 1 y ss., y con cierta ironía se pregunta: ¿Qué hay en el número 5 que lo hace ser preferido a otros mayores o menores a la hora de decidir convertirlo en el plazo general de prescripción? En un sentido parecido respecto del plazo para la prescripción en los seguros de responsabilidad civil extracontractual, Rafael La Casa, Defensa jurídica y dolo del asegurado en el seguro de responsabilidad civil (Madrid: Fundación Mapfre, 2017), 22. 
titéticos, pero cruciales en el devenir mismo de la institución ${ }^{112}$. ¿Cuál es, en suma, el objeto real de la prescripción? ${ }^{113}$ No cabe duda en torno a los efectos del instituto, pero sobre qué se proyectan esos efectos, ¿sobre Derechos subjetivos?, ¿Derechos indisponibles?, ¿Derechos de crédito?, ¿Derechos sobre cosa ajena? ${ }^{114}$

\section{La derogabilidad de la prescripción y el pactum de non petendo.}

La prescripción es una institución que asienta sus principios en el orden público, la seguridad a las relaciones jurídicas habida cuenta que al derecho le repugnan las vinculaciones perpetuas y, en cierto modo, en la imperatividad de la norma ${ }^{115}$. Pero sustentar y anclar una institución en principios, en retórica, deja un cierto halo de indefinición, de escasez de argumentos reales, concisos que a la postre le doten de un sentido práctico y efectivo.

Por mucho que los principios asientan y alfombran los ámbitos y parcelas de nuestras normas positivas. Señalaba la vieja sentencia del Tribunal Supremo de 13 de abril de 1956 como «la prescripción de las pretensiones en general sirve a la seguridad del Derecho y a la paz jurídica, las cuales exigen que se ponga un límite a las pretensiones jurídicas envejecidas, ya que sin la prescripción nadie estaría a cubierto de pretensiones sin fundamento o extinguidas de antiguo».

Quedarnos solo en la vaguedad de la idea de los efectos jurídicos que tiene el plazo inexorable del tiempo es solo situar el foco y el análisis sesgadamente sobre una de las aristas de esta institución poliédrica. Es la certidumbre, la que late en el fondo y finalidad de este instituto. La certeza de relaciones que se consolidan, pero que no penden sine die en el tiempo con toda la relatividad, pero también, conflictividad que conlleva. Romper con

112 Magistrales Alas/De Buen/Ramos, De la prescripción..., 51 aducían como no es un silencio físico, ciertamente. Es un silencio que por parte del acreedor se traduce en dos hechos: el no ejercicio ante los tribunales y la no reclamación extrajudicial del acreedor; y por parte del deudor, en no realizar ningún acto de reconocimiento de la deuda.

113 Afirma Troisi, $L a$ prescrizione..., 27: «la prescrizione si presenta come un instituto di applicazione per l'appunto generale e astratta, a dispetto di ogni possibile specificità delle concrete situazioni giuridiche soggettive; e quando delle discriminazioni vengono operate, queste, atinente peraltro alla mera disciplina, prendono in considerazioni soltanto i profili strutturali e mai quelli funzionali, certamente piú rilevanti».

114 Defienden su proyección a todos los derechos indistintamente, Azzariti/Scarpello, Prescrizione..., 203 y ss. reconduciendo su aplicabilidad únicamente a los derechos de crédito, Francesco Carnelutti, «Appunti sulla prescrizione», Riv. dir. proc. civ.,vol. I (1933): 47.

115 Crítico con esta visión de orden público, paz en las relaciones jurídicas, seguridad, etc., Matthias Storme, «Perspectieven voor de bevrijdende verjaring in het vermogensrecht (Met ontwerpbepalingen voor een hervorming)», T.P. R., n. 34 (1994): 2018. 
la inercia de la facticidad a situaciones de derecho definitivas ${ }^{116}$. Es la ley la que norma, configura y edifica el pilar prescriptivo ${ }^{117}$. Pero ¿cabría hablar o referenciar en la prescripción un «derecho-poder»? ${ }^{118}$

La que dicta y exige plazos, la que conforma los inicios de los cómputos, pero es la práctica la que rompe esquemas de unicidad y con su basta y compleja a la vez casuística. O la que permite, como en algunas regulaciones que, amén de un plazo general, las pólizas puedan establecer otro ${ }^{119}$.

116 Así, podemos leer en la sentencia del Supremo de 7 de enero de 1958 argumentos sólidos como: «la opinión científica, la legislación y la doctrina jurisprudencial reconocen la existencia de la prescripción como institución necesaria que sirve para asegurar la estabilidad económica, transformando en situación de Derecho la que sólo era de mero hecho, ya que sin este medio, la propiedad y los derechos todos estarían expuestos a la incertidumbre e inseguridad jurídica impropia de lo que constituye su esencia».

117 Ello no impide que esa misma norma se supedite, por ejemplo, en el ámbito del contrato de seguro, a lo que se establezca respecto de los plazos de prescripción en la propia póliza y, en ausencia, el dictado legal. Un dictado que puede no ser uniforme y que varíe, como sucede entre los distintos estados de Estados Unidos, de fechas. O a remisiones muy vagas o genéricas, como en Reino Unido en el que los contratos de seguro están supeditados a los plazos generales de Limitation Act 1980 para aquellas acciones fundadas sobre incumplimientos o rupturas de contrato (seis años), si bien la Enterprise Act 2016 «gives policyholders a legal right to enforce prompt payment of insurance claims». O en el supuesto austríaco en el que la Sección 12 de la VersVG establece un plazo generalemente de tres años, más eso sí, con la peculiaridad de que en caso de denegar la cobertura la aseguradora, ésta puede imponer al asegurado que presente una demanda dentro del plazo de un año declarando la denegación de cobertura calificada y en la que se especifican las razones de denegación de cobertura por parte de aquélla. En Canadá varía según la ley aplicable de cada Provincia; en Ontario el plazo es de dos años desde el momento en que se produce el siniestro por lo que la reclamación ha de hacerse en ese tiempo, tiempo que baja a un año en supuestos de seguros de incendio o de motor.

118 Sobre este punto Stijns/Samoy, «La prescription extinctive: le rôle de la volonté et du comportement des parties», 344 y donde ejemplifican como la renuncia por medio de la prescripción puede ser calificada como derecho-poder dado que la decisión unilateral del deudor actuará sobre su posición jurídica propia y sobre la de su acreedor. Un derecho-poder es un derecho que confiere a su titular el poder de actuar sobre su propia situación jurídica o sobre la de otro por un acto unilateral que puede afectar o apuntar a la creación, a la extinción o a la modificación de la situación jurídica preexistente.

119 No son pocos los estados norteamericanos que establecen esta posibilidad. Así, al plazo general de seis años para presentar una demanda por incumplimiento de contrato, pero se permite que las pólizas de seguro regulen esta cuestión, situándose normalmente el umbral en doce meses. Otra cuestión es saber y marcar cuándo efectivamente arrancan estos doce meses, máxime tras ciertas declaraciones y pruebas de pérdida que el asegurado ha de realizar. Así en el estado de Arizona «permits parties to contract around the statutory time period of six years and for a shorter time period. Specifically, A.R.S. §20-1115 permits a limitation of no less than one year from the date of occurrence in property, marine, and transportation policies, and no less than two years in all other types of insurance policies. Any policy that tries to shorten the statute of limitations to under a period of one year, however, is void under Arizona law». Como podemos ver sitúa el umbral entre 1 año y 2 en función del tipo de póliza y veta todo pacto o imposición que cercene esos umbrales empeorando la situación del asegurado. 


\section{Acortación y alargación de plazos. Desafío convencional a una imperatividad antigua}

De antiguo se ha discutido, pero también cuestionado, tanto la imperatividad de las normas positivas sobre la prescripción, como, en ese conciso ámbito, el rol o espacio de margen efectivo para la libre negociación y disposición de las partes sobre extremos de la prescripción. Mas, ¿pueden las partes en aras de la autonomía de la voluntad derogar, mudar, cambiar plazos, cómputos o incluso renunciar a la prescripción misma? ${ }^{120 / 121}$ Contundente la respuesta sin embargo que nos prodiga la sentencia del Supremo de 3 de julio de 2018 cuando en su fundamento segundo concluye:

«... que la prescripción de acciones es una excepción que se debe examinar con mucho cuidado en los casos en que la misma se alegue, como se dice en el recurso, es algo obvio para cualquier tribunal, como ocurre con cualquier otra cuestión que se someta a su consideración. Es doctrina reiterada de esta Sala la que señala que una cosa es que el plazo de prescripción de un año establecido en nuestro ordenamiento jurídico para las obligaciones extracontractuales sea indudablemente corto y que su aplicación no deba ser rigurosa sino cautelosa y restrictiva, y otra distinta que la jurisprudencia pueda derogar, por vía de interpretación, el instituto jurídico que nos ocupa, pues ello aparece prohibido por el ordenamiento jurídico. El plazo prescriptivo es improrrogable y no es posible una interpretación extensiva de los supuestos de interrupción.»

Y un paso más, ¿pueden hacerlo sin con ello no se causa perjuicio a ninguna de las dos partes de la relación jurídica? ${ }^{122}$ Y los plazos de pospo-

120 Ofrecen las condiciones necesarias o requisitos que habría de tener semejante cláusula, así, Robert Keeton/Alan Widiss/James Fischer, Insurance Law (St. Paul: West Academic Publishing, 2017), 847 admitiendo este recorte temporal siempre que: «a contractual provision in an insurance policy prescribing a time period - which is shorter than the time period specified in the applicable statute of limitations - is enforceable if (1) it is clear and unambigous, (2) is not contraty to the reasonable expectations of the insured, (3) it is not unreasonable in length, and (4) it is not unconscionable».

121 Advierte, Véronique Nicolas, Droit des contrats d'assurances (Paris: Editorial Económica, 2012), 353 quien en base al art. 114-3 del código de seguros, las partes del contrato de seguro no pueden, ni siquiera de común acuerdo modificar la duración de la prescripción «ni ajouter aux causes de suspension ou d'interruption de celle-ci», la contradicción y lo erróneo del artículo respecto a la posición del Code artículo 2254 en el que caben acuerdos convencionales sobre la prescripción

122 Véase la aportación de Andrés Domínguez Luelmo, «Alteración convencional de los plazos de prescripción extintiva en derecho de obligaciones», en Estudios jurídicos en homenaje al profesor Luis Díez-Picazo, vol. I, ed. por Antonio Cabanillas (Madrid: Civitas, 2002), 
sición o aquellos de preclusión necesarios que algunos ordenamientos foráneos exigen antes de que empiece a transcurrir el cómputo prescriptivo y que se traducen en algunas obligaciones de hacer?

La práctica ha conocido, sobre todo, en el pasado, supuestos de esa derogabilidad impuesta siquiera parcial y temporalmente por la parte fuerte del contrato, máxime ante los silencios lacunosos del legislador ${ }^{123}$. Escapa a la voluntad de las partes, dado que la regulación es legal y no convencional, la derogación parcial o particular de la prescripción, por lo que las partes no pueden en el contrato disponer libremente de los plazos sea acortándolos, sea alargándolos, prescriptivos tasados por la ley; ${ }^{124}$ la prescripción no es disponible, no es elástica ni plegable a la voluntad de las partes; de

473 y ss. Señalaba Joaquín Garrigues, Contrato de seguro terrestre (Madrid: Imprenta Aguirre, 1973), 117 como al no decir nada la ley sobre si era posible acortar los plazos a favor del asegurador y en perjuicio del asegurado «claro está que a favor de la libertad de las pólizas se puede aducir el argumento de que existe una laguna legal que deja en libertad a los contratantes para fijar el plazo de prescripción, y que ese plazo convencional ha sido objeto de examen por las autoridades de control, y lo han estimado aceptable». Contundente Antigono Donati, Trattato del diritto delle assicurazioni private, tomo II (Milano: Giuffrè, 1954) 521 señalaba: «... non può più riconoscersi validità alle clausole sopraricordate che modificano comunque la disciplina legale (termini, decorrenza, sospensione, interruzione) della prescrizione e oportunamente le polizze ormai le omettono».

${ }^{123}$ Cuestión distinta es que una norma lo permita, como se ha reseñado en nota supra. En el caso Zuckerman v. Transamerica Ins. Co., 133 Ariz. 139, 650 P.2d 441 (Ariz. 1982), la Corte Suprema del estado, guiada por los principios de equidad y orden público adveró: «[W] hile the policy condition shortening the applicable statute is valid...the insurer may be estopped from raising a defense based upon such an adhesive clause where the enforcement of the clause would work an unjust forfeiture. The key factor in the determination of this issue is the question of whether the insurer has shown prejudice by reason of the delay in filing suit. In the absence of such a showing, it is fair to say that the purpose for which the insurer was given permission to insert the clause will not be served by its enforcement».

${ }^{124}$ Cuestión distinta es cuando la flexibilidad y disponibilidad permite que la legislación establezca unos plazos genéricos y que los concretos términos de una póliza señalen otros diferentes. En algunas legislaciones estatales estadounidenses se permite esto, incluso que la póliza acorte ese plazo normalmente a un año frente a los cuatro o seis genéricos. Contrasta sin embargo con la legilación de Texas en la que según la sección o parágrafo 16.070(a) of the Texas Civil Practice \& Remedies Code states that a person may not enter a contract or agreement «that purports to limit the time in which to bring suit on the . . contract to a period shorter than two years». Policy provisions establishing a contractual limitations period less than two years and subject to this statute are void and unenforceable. Es decir, si la póliza establece un plazo menor, el pacto es nulo. Así, por ejemplo, Noah Nadler, 1 de abril de 2019, «Is an insurance policy's statute of limitation clause enforceable?», Lexology, 28 de octubre de 2013, https://www.lexology.com/library/detail aspx?g=4c1982f9-ed6d-435c-854bee0acaec54a4, pregunta: «Cuando el período de limitaciones contractuales - prescripciónde una póliza es nulo, la pregunta se convierte en: ¿qué plazo de prescripción se aplica a una reclamación por incumplimiento de contrato? Si la disposición de limitaciones contractuales no contiene una savings clause, se aplicará el período de limitación legal predeterminado para el incumplimiento de las reclamaciones contractuales». 
lo contrario se distorsiona la finalidad misma y esencia del instituto que, se ha caracterizado por el rigor y cierta impermeabilidad dogmática ${ }^{125}$. Pero ¿debería cambiar esta premisa máxime teniendo en cuenta el dictado de las normas principiales en el derecho comunitario y el sentido de alguna de las reformas operadas en algún país próximo? ${ }^{126}$

Acortar plazos si éstos son de suyo ya breves perjudica al acreedor, si no se interrumpe la pretensión del acreedor y beneficia al deudor, y alargarlos, perjudica la expectativa de liberación del deudor, pero ¿es más onerosa la acortación de plazos? ?27, o en cambio, ¿lo sería una prolongación encadenada de los mismos? ${ }^{128}$ ¿Qué espacio queda entonces para esta derogabilidad convencional de las partes alargando o acortando plazos prescriptivos? Verdaderamente ¿se produce un perjuicio si se alarga el plazo? Y en este caso, ¿para quién? ${ }^{129}$

125 No pierden al menos curiosidad las palabras sobre el giro que hubo en la negociabilidad en los condicionados de Jean Carbonnier, «Notes sur la prescription extinctive», RTDciv., vol. 50 (1952): 176: «L'expérience [écrivait-il] a montré que le péril avait changé de cmap, et que, dans des contrats d'adhésion, des débiteurs tout-puissants pouvaient imposer à leurs créanciers des prescriptions conventionnelles d'une brièveté captieuse. Le législateur a dû intervenir pour prohiber ces clauses abréviatives là où l'abus en avait été particulièrement criant, dans le contrat d'assurance».

126 Indica Anna Guégan, «La prescription en droit des assurances», en La prescription extinctive. Études de droit comparé, editado por Patrice Jourdain y Patrick Wéry (Bruxelles: Bruylant, 2010), 596: «Ce ne sont pourtant pas les appels à la réforme de la prescription biennale qui manquaient, qu'il s'agisse de ceux de la doctrine ou même de ceux de la Cour de cassation, qu'il s'agisse d'allonger le délai de prescription, ou bien de le rendre asymétrique en l'allongeant pour les assurés tout en le raccourcissant pour les assureurs, ou bien encore d'ajouter des dispositions favorables aux assurés trop souvent malmenés par une prescription dont ils ne saisissent pas les travers et dont ils maîtrisent mal le fonctionnement».

127 A favor del acortamiento, no del alargamiento, Alas/De Buen/Ramos, De la prescripción..., 261: «no vemos inconveniente para ello. Las partes pueden acordar que el transcurso de la prescripción extintiva sea más corto, sin faltar a la finalidad primordial de la prescripción extintiva, que es la seguridad de las relaciones de derecho».

128 Para Alas/De Buen/Ramos, De la prescripción..., 260 alargar el plazo más allá del acordado por la ley, significaría en realidad una renuncia parcial a las ventajas que la prescripción extintiva reporta, ya que se sujetaría a mayores dificultades el cumplimiento de la prescripción. Advierten que el riesgo de este alargamiento sería el de llegar por un procedimiento indirecto, a una renuncia anticipada.

${ }^{129}$ Categóricos sobre esta interdicción d’allonger, Stijns/Samoy, «La prescription extinctive: le rôle de la volonté et du comportement des parties», 345 para quiénes están prohibidas por la ley, constituyendo una renuncia parcial al beneficio de una prescripción futura, por lo que estas cláusulas pactadas en la conclusión del contrato, son alcanzadas por la prohibición del art. 2220 del Code civil. Ellas frenan el decurso natural de la prescripción y van en contra del dictado del legislador de evitar la negligencia de los acreedores. Tal cláusula podría «même aboutir, par une prolongation considérable de la durée du délai, à empêcher la precription de se produire». 
Acortar es renunciar a una prescripción futura y aún no ganada, pero, ¿realmente es esto así y se puede decir que causa un perjuicio o debemos por el contrario permitir su licitud? ${ }^{130}$ Abreviar el plazo parece, al menos, que se beneficia al deudor, se le refuerza en su protección dado que, transcurrido un plazo más breve, la liberación es más próxima ${ }^{131}$. ¿Supone un abuso en la autonomía contractual? Pensemos en cualquier otro ámbito del derecho financiero, como préstamos con interés. Así, tomar como punto de partida del cómputo del plazo un evento o una fecha anterior, sin duda, acorta el plazo, sin que necesariamente el mismo sea más breve, simplemente el inicio del cómputo se retrotrae a un hecho o a una fecha que es anterior a aquél que, en puridad configura el derecho accionable y, por ende, tutelable.

Pero admitir el acortamiento de plazos solo es dable si efectivamente las normas sobre la prescripción en el código civil y mercantil, pues no las hay en la LCS salvo la brevedad del artículo 23 para marcar la dualidad de años en función de los dos clásicos ramos, se conciben como derecho dispositivo por voluntad y acuerdo de las partes y no normas imperativas o de orden público. Y es dable además si el acreedor que todavía no lo es seguramente en el momento de negociar este acortamiento, tendría en su caso un tiempo o tempus suficiente y razonable para ejercer sus derechos o, cuando menos, accionar una causa interruptiva que rompa o quiebre totalmente el decorrer prescriptivo.

Si el acreedor no tuviere la posibilidad real de ejercitar y tutelar, exigiendo su pretensión, la misma sería abusiva, inequitativa y desproporcional por su onerosidad para una de las partes de la relación jurídica ${ }^{132}$. Cabe, en un terreno ahora mismo de hipótesis hacer la siguiente comparación, a saber, si comparamos el acortamiento de plazos con la posibilidad de que

130 A favor de esta licitud para las cláusulas que abrevian los plazos prescriptivos, Bénédicte Humblet/Raphaël Davin, «La prescription extinctive en droit civil», en Les prescriptions et les délais (Liège: Éditions du Jeune Barreau de Liège, 2007), 11. También, Maxime Marchandise, «La prescription libératoire en matière civile», Doss. du J.T., n. ${ }^{\circ} 64$ (2007): 65.

131 Observa Carbonnier, «Notes sur la prescription extinctive», 176 como la experiencia muestra el peligro y los cambios que se vieron en los contratos de adhesión, en el que los deudores todopoderosos, pueden imponer a sus acreedores prescripciones convencionales de una brevedad «captieuse ou trompeuse». Señalan Stijns/Samoy, «La prescription extinctive: le rôle de la volonté et du comportement des parties», 347: «Pour la même raison, une clause qui prend comme point de départ du délai un fait ou une date antérieurs à l'événement visé par la loi, revient indirectement à une réduction du délai de prescription et est valable».

132 Stijns/Samoy, «La prescription extinctive: le rôle de la volonté et du comportement des parties», 348 traen a colación una póliza de seguro que previó que «sera prescrite par un an écoulé à partir du jour de l'accident, toute réclamation de garantie ou d'indemnité qui n’ayant pas été admise, n’aura pas été portée devant le tribunal compétent». Señalan los autores que para la Corte de apelación de Mons, semejante clásusula de acortar el plazo es nula en tanto «qu'elle vise l'action en garantie». 
las partes puedan suspender de mutuo acuerdo la prescripción ya iniciada porque entre ellas han decidido iniciar conversaciones, o incluso que dirima el potencial conflicto crediticio un tercero experto, $i$ acaso no es, mutatis mutandis, una situación similar a la del acortamiento de plazos? ?33 $^{133}$

Alargar es renunciar parcialmente al beneficio de una prescripción futura $^{134}$. Y alargar también se puede realizar de un modo indirecto, al manipular, obstruir o tratar de cambiar o evitar pautas claras y concisas en la enorme pragmaticidad y riqueza casuística que tiene el seguro, el inicio del cómputo para la prescripción ${ }^{135}$. Pero ¿acaso y si en una renegociación, aunque la misma sea impuesta, acaso no es factible que las partes acuerden la sustitución o novación de una obligación por otra convirtiendo la prescripción en una quimera? Si bien conviene no confundir que un mero, pero explícito, reconocimiento de deuda por parte del obligado en modo alguno puede convertirse en una novación de la obligación, por lo que las partes hacen no es en puridad prolongar la relación jurídica primigenia, sino novarla, objetivamente, renegociando la parte económica o más onerosa de la relación.

\section{Conclusión}

Esta centenaria institución cobra hoy, en 2019, todo su protagonismo y fundamento. Por mucho que se busque éste, no es sino la más genuina expresión de un efecto negativo que el transcurso del tiempo depara para una relación jurídica. Cómo y por qué de una figura que es el espejo de implícita expropiación de valor de un crédito ante la inactividad del titular del mismo.

133 Por esta vía apuntan Marchandise, «La prescription libératoire en matière civile», 25; también, Bernard Dubuisson/Vincent Callewaert, «La prescription en droit des assurances», Revue Générale des Assurances et des Responsabilités, vol. 84 (2011): 637 y lo hacen porque el derecho civil, no se opone a esta situación y, por tanto, cabría extrapolarla al contrato de seguro.

${ }^{134}$ Semejantes cláusulas rompen el equilibrio y hacen muy oneroso para una de ellas, el desarrollo normal y lógico de la prescripción y en todo caso, son un mecanismo que premia, al alargar el plazo, la inactividad, por tanto, la negligencia de los acreedores. En parecidos términos, Stijns/Samoy, «La prescription extinctive: le rôle de la volonté et du comportement des parties», 346 que señala como una tal cláusula podría asimismo conducir a una prolongación considerable de la duración del plazo prescriptivo. Así, el Tratado CMR en unc onrato de trasnporste no permite excepciones a la corta prescripción de seis meses del artículo 9 de la Ley del Transporte, y reemplazarlos por los plazos más largos del Tratado.

135 Alerta de estas maniobras indirectas que buscan por esta vía este alargamiento de los plazos de prescripción, Stijns/Samoy, «La prescription extinctive: le rôle de la volonté et du comportement des parties», 346, no obstante señala: «Par contre, la prohibition ne touche pas l'hypothèse où les parties substituent une obligation à une autre, dont la prescription est soumise à delais plus court et où elles modifient, dès lors, le titre de la dette». 
Sin embargo, las aristas, los problemas, las dificultades interpretativas siguen, hoy al igual que ayer, presentes. Nada tienen que ver las viejas regulaciones codiciales con los nuevos impulsos que trae el soft law a través de corpus principiales que están aggiornando la prescripción [significativamente los PECL y el DCFR]. Sin embargo, una vez más, nuestro país, a diferencia de lo que está sucediendo en otros, tanto a nivel comunitario, como internacional comparado está al margen del gran debate reformador de la prescripción al menos de lege ferenda que no doctrinalmente.

Debilita y extingue un derecho, pero presenta no obstante una riqueza dogmática y práctica, inconmensurable, al tiempo de que su razón de ser no se funda precisamente en anclajes de justicia o equidad intrínseca. Equidad que va más allá del alargamiento o por el contrario, acortamiento de plazos que analizamos en este artículo.

\section{Sobre el autor}

Abel B. Veiga Copo (Madrid, 1972) es profesor propio agregado de Derecho Mercantil de la Universidad Pontificia Comillas de Madrid (ICADE). Se doctoró en Derecho por la misma Universidad y estudió en la UNED la Licenciatura en Ciencias Políticas y Sociología. Sus áreas de trabajo en derecho mercantil se centran en el derecho del seguro, con su monumental Tratado de contrato de seguro (sexta edición-junio de 2019 y 4.800 páginas), así como el derecho de garantías mobiliarias, el derecho concursal y el derecho de sociedades. De 2013 a 2016 fue Director de Internacionalización en la Xunta de Galicia (Igape). Es columnista de opinión en una veintena de periódicos nacionales y alguno internacional.

\section{About the Author}

Abel B. Veiga Copo (Madrid, 1972) is Professor of Commercial Law at the Universidad Pontificia Comillas de Madrid (ICADE). He received his doctorate in Law from the same University and studied at the UNED a degree in Political Science and Sociology. His areas of work in commercial law are focused on insurance law, with his monumental Insurance Contract Treaty (sixth edition-June 2019 and 4,800 pages), as well as the law of security interests, the bankruptcy law and the law to societies. From 2013 to 2016 he was Director of Internationalization in the Xunta de Galicia (Igape). He is an opinion columnist in a score of national and international newspapers. 


\section{Derechos de autor}

Los derechos de autor (para la distribución, comunicación pública, reproducción e inclusión en bases de datos de indexación y repositorios institucionales) de esta publicación (Cuadernos Europeos de Deusto, CED) pertenecen a la editorial Universidad de Deusto. El acceso al contenido digital de cualquier número de Cuadernos Europeos de Deusto es gratuito inmediatamente después de su publicación. Los trabajos podrán leerse, descargarse, copiar y difundir en cualquier medio sin fines comerciales y según lo previsto por la ley; sin la previa autorización de la Editorial (Universidad de Deusto) o el autor. Así mismo, los trabajos editados en CED pueden ser publicados con posterioridad en otros medios o revistas, siempre que el autor indique con claridad y en la primera nota a pie de página que el trabajo se publicó por primera vez en CED, con indicación del número, año, páginas y DOI (si procede). Cualquier otro uso de su contenido en cualquier medio o formato, ahora conocido o desarrollado en el futuro, requiere el permiso previo por escrito del titular de los derechos de autor.

\section{Copyright}

Copyright (for distribution, public communication, reproduction and inclusion in indexation databases and institutional repositories) of this publication (Cuadernos Europeos de Deusto, CED) belongs to the publisher University of Deusto. Access to the digital content of any Issue of Cuadernos Europeos de Deusto is free upon its publication. The content can be read, downloaded, copied, and distributed freely in any medium only for non-commercial purposes and in accordance with any applicable copyright legislation, without prior permission from the copyright holder (University of Deusto) or the author. Thus, the content of CED can be subsequently published in other media or journals, as long as the author clearly indicates in the first footnote that the work was published in CED for the first time, indicating the Issue number, year, pages, and DOI (if applicable). Any other use of its content in any medium or format, now known or developed in the future, requires prior written permission of the copyright holder. 